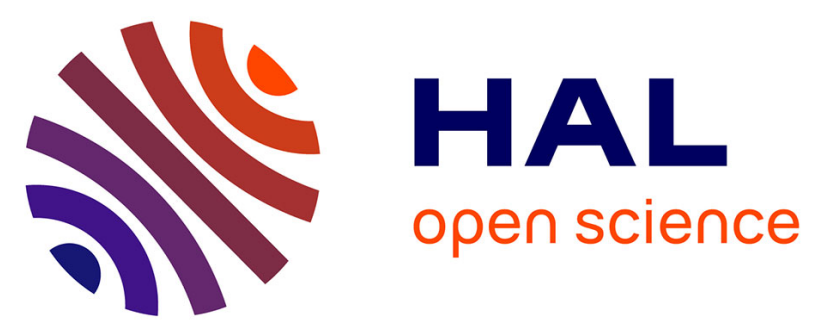

\title{
Taxonomic revision of the genus Monastria Saussure, 1864 (Blattodea: Blaberidae, Blaberinae) from the South American Atlantic forest, with the descriptions of five new species
}

Vitor Dias Tarli, Philippe Grandcolas, Roseli Pellens

\section{To cite this version:}

Vitor Dias Tarli, Philippe Grandcolas, Roseli Pellens. Taxonomic revision of the genus Monastria Saussure, 1864 (Blattodea: Blaberidae, Blaberinae) from the South American Atlantic forest, with the descriptions of five new species. Zootaxa, 2018, 4524 (3), pp.359-391. 10.11646/zootaxa.4524.3.5 . hal-02313543

\author{
HAL Id: hal-02313543 \\ https://hal.science/hal-02313543
}

Submitted on 11 Oct 2019

HAL is a multi-disciplinary open access archive for the deposit and dissemination of scientific research documents, whether they are published or not. The documents may come from teaching and research institutions in France or abroad, or from public or private research centers.
L'archive ouverte pluridisciplinaire $\mathbf{H A L}$, est destinée au dépôt et à la diffusion de documents scientifiques de niveau recherche, publiés ou non, émanant des établissements d'enseignement et de recherche français ou étrangers, des laboratoires publics ou privés. 

- CP 50, Muséum national d'Histoire naturelle, Sorbonne Universités, 45, rue Buffon, 75005 Paris,

${ }^{2}$ CAPES Foundation - Ministry of Education of Brazil, Brasilia - DF, 70040-020, Brazil

$9 \quad{ }^{3}$ Corresponding author.E-mail:vitor_tarli@hotmail.com

Abstract

The genus Monastria Saussure, 1864 includes medium to large sized (40-55 mm) dark brown or black cockroaches found in the understory of the Neotropical Atlantic Forest from the Northeast of Brazil to Paraguay and Argentina. The genus shows evident sexual dimorphism: males are elongated with fully developed wings extending beyond the apex of cerci and females are oval and brachypterous. This study is a revision of the genus with redescription of the three already known species, Monastria biguttata (Thunberg, 1826), Monastria similis (Serville, 1838) and Monastria angulata Saussure, 1864, and description of five new ones, Monastria itubera sp. n. and Monastria itabuna sp. n. from state of Bahia, Monastria cabocla sp. n. from state of Sergipe, Monastria kaingangue sp. n. from state of São Paulo and Monastria sagittata sp. n. from state of Minas Gerais. The morphology of the genus and all species is described in details, including male genitalia. Based on this revision, we proposed a new combination for Hiereoblatta papillosa (Thunberg, 1826) comb. n., excluding it from the genus Monastria. For the first time, the juvenile stages of Monastria are characterized and compared to other genera of Blaberinae of the Atlantic forest. Three determination keys are provided. The two first are aimed at identifying the adults and juvenile stages of the five genera of the Blaberinae radiation endemic to the Atlantic forest, respectively. The third concerns the identification of the species of the genus Monastria. A map indicating the localities where species were sampled is also provided.

Key Words: Neotropical Atlantic Forest,, endemic cockroach, male genitalia, juvenile stages, distribution range, review.

\section{Resumo}

O gênero Monastria Saussure, 1864a inclui baratas de tamanho médio a grande (40 - $55 \mathrm{~mm}$ ), marrom escura ou negra, encontradas no sub-bosque da floresta Atlântica neotropical do Nordeste do Brazil até 
com asas longas completamente desenvolvidas se estendendo além do ápice dos cercos e as fêmeas são braquípteras e ovais. Este estudo é uma revisão do gênero com re-descrição das três espécies conhecidas, Monastria biguttata (Thunberg, 1826), Monastria similis (Serville, 1838) e Monastria angulata Saussure, 1864a e descrição de cinco novas espécies: Monastria itubera sp. n. e Monastria itabuna sp. n. do estado da Bahia, Monastria cabocla sp. n. do estado de Sergipe, Monastria kaingangue sp. n. do estado de São Paulo e Monastria sagittata sp. n. do estado de Minas Gerais. A morfologia do gênero e de todas as espécies é descrita em detalhes, inclusive a genitália do macho. Com base nesta revisão, nós propusemos uma nova combinação para Hiereoblatta papillosa (Thunberg, 1826) comb. n., excluindo-a do gênero Monastria. Pela primeira vez o estágio juvenil deste gênero é caracterizado e comparado com os de outros gêneros de Blaberinae da Mata Atlântica. Três chaves de determinação são fornecidas. As duas primeiras são destinadas a identificar os adultos e juvenis dos cinco gêneros da radiação de Blaberinae endêmica da Mata Atlântica, respectivamente. A terceira concerne a identificação das espécies do gênero Monastria. Um mapa indicando as localidades onde as espécies foram coletadas também é fornecido.

\section{Introduction}

Cockroaches have evolved with diverse continental radiations. One of the most conspicuous corresponds to the subfamilies Zetoborinae (Grandcolas, 1993a; Grandcolas \& Pellens, 2002; Brugerolle et al. 2003; Pellens et al. 2002; 2007a) and Blaberinae distributed in the Neotropical region (Grandcolas 1993b, c, 1998; Pellens \& Grandcolas, 2007; Pellens et al. 2007b; Grandcolas \& Pellens, 2012; Legendre et al., 2015). Blaberinae, an early-recognized group (McKittrick, 1964; Roth, 1970a, 2003), has been the subject of several behavioral and ecological studies (Grandcolas, 1998). Despite this early recognition, some of its components have been poorly studied, such as the genera endemic from the Atlantic forest in Brazil, namely Monastria Saussure, 1864a, Monachoda Burmeister, 1838, Petasodes Saussure, 1864, Hiereoblatta Rehn, 1937, and Minablatta Rehn, 1940 (Grandcolas 1993b,c, 1998; Pellens et al. 2007b; Grandcolas \& Pellens, 2012). The genus Monastria Saussure, 1864a is certainly the best known amongst them (Pellens \& Grandcolas, 2003, 2007). Nevertheless, its taxonomy needs a complete revision.

The genus Monastria was erected by Saussure (1864a), two previously known species Blatta biguttata Thunberg, 1826 and Blabera similis Serville, 1838 were transferred to Monastria and described two new taxa Monastria angulata and Monastria semialata. Walker (1868) included the known species of Monastria in his catalogue. He also described a new species and new genus Tarraga guttiventris and a new species Blabera nigripennis of cockroaches that were subsequently brought back into Monastria. Kirby (1904) recognized that Monastria semialata (Saussure, 1864a) was a synonym of Monastria cassidea (Eschscholtz, 1822), Blabera nigripennis (Walker, 1868) was a synonym of M. biguttata, and Monachoda granosa Brunner von Wattenwyl, 1865 was a synonym of Monastria papillosa. He also 
incorrectly synonymized Tarraga gutiventris with Blaberus giganteus (Linnaeus, 1758). Shelford (1907-1908) in his study on the species published by Thunberg incorrectly synonymized Monastria semialata (Saussure, 1864a), Monachoda granosa Brunner von Wattenwyl, 1865 and Phoraspis cassidea (Dalman, 1823) with Monastria papillosa (Thunberg, 1826). In the same study Blabera monstrosa Stål, 1855 was considered a synonym of Monastria biguttata (Thunberg, 1826). Kirby (1910) published a correction in which Blatta papillosa Thunberg, 1826 was synonymized with Monastria cassidea (Eschscholtz, 1822). Rehn (1937) described the genus Hiereoblatta and accepted Monastria semialata (Saussure, 1864a) as the only synonym of Hiereoblatta cassidea (Eschscholtz, 1822). Princis (1946) described Monastria flavomarginata, but in 1951 he stated that it was a synonym of Monastria similis (Serville, 1838). Princis (1949) maintained Blatta papillosa Thunberg, 1826 as a synonym of Monastria papillosa (Thunberg, 1826). In 1958, Princis synonymized Tarraga gutiventris Walker, 1868 with M. biguttata (Thunberg, 1826). In the catalogue published in 1963, Princis included four valid species to the genus: Monastria angulata Saussure, 1864a; Monastria biguttata (Thunberg, 1826); Monastria papillosa (Thunberg, 1826); Monastria similis (Serville, 1838). In the present study, we revised the genus Monastria.

\section{Material and Methods}

Specimens were measured with a digital caliper and stereoscopic microscope Leica MZ12 equipped with an eyepiece micrometer scale. Measurements of interocular and interantennal distance and genitalia were taken. After dissection of a re-hydrated specimen, its genitalia was treated in cold $10 \%$ $\mathrm{KOH}$ to remove remains of soft tissue and rinsed with water. Finally, it was kept in glass vial with glycerin and pinned under the specimen. Nomenclature of male genitalia sclerites follow Grandcolas (1996), modified from Grandcolas (1991, 1993c). Abbreviations: L1, L2d, R2, R3d, N, R3v, Lb (Lateral Branch), Cs (Crown of spines), Notch (Subapical incision) and Clf (Cleft).

Digital images of habitus, pronotum, head, supra-anal plate and juvenile stages were taken with a camera Cannon 6D. Genital sclerites were photographed with a stereomicroscope Nikon attached to a camera Cannon 6D. Images of external morphology and genitalia were combined with the Helicon Focus 6.7.1 software and edited in Adobe Photoshop Elements 11. The cuticle of juvenile stages of five specimens were critical point dried, coated with gold-palladium and digitally photographed using a HITACHI SU3500 scanning electron microscope.

The material examined are part of the collections of the following institutions: Muséum National d'Histoire Naturelle in Paris (MNHN), Muséum d'Histoire Naturelle de la Ville de Genève (MHNG), Natural History Museum London (NHM), Museu de Zoologia Universidade de São Paulo (MZUSP), Museu Nacional do Rio de Janeiro (MNRJ) and Uppsala University Museum of Evolution, Uppsala in Sweden (UUZM). 
Key to the genera of the subfamily Blaberinae endemic from the Neotropical Atlantic forest

116 Adults

1171 Pronotum with lateral margin rounded, without notch or spine ... 2

118 - Pronotum with lateral margin inclined, most often with a notch or a spine ... 3

1192 Pronotal cuticle smooth; dark brown with two orange spots; male brachypterous (Fig. 1C) ...

\section{Minablatta Rehn}

121 - Pronotum strongly gibbous; yellow darker in the middle; male brachypterous (Fig. 1D) ...

$122 \quad$ Hiereoblatta Rehn, 1937

1233 Pronotum unicolored (tawny beige); fore margin very abruptly curved upward. The head ventrally

124 inserted strongly protruded (Fig.1B) ... Petasodes

125 - Pronotum with a more complex coloration; roughly triangular; lateral margin inclined most often 126 with a notch or a spine ... 4

1274 Pronotum smooth, with a very light prominence above the head and a black complex spot in the 128 postero-central area and reaching the posterior margin (Fig. 1E) ... Monachoda Burmeister

129 - Pronotum gibbose, with a complex dark and brightly-colored pattern in the middle (Fig. 1A) ...

\section{Monastria Saussure}

\section{Juvenile stages}

1331 Pronotum hind margin nearly straight ... 2

134 - Pronotum hind margin not straight ... 3

1352 Dorsal surface totally covered by very abundant long thorn-like spines (including pronotum) with a row of larger spines at hind margins; supra anal plate bilobed with a deep incision; each lobe forming straight angles; hind region wider (Figs. 2E, 3E) ... Monachoda Burmeister

138 - Dorsal surface covered by microsculptures formed by triangular spines, except pronotum; supra-anal plate bilobed with a very small median incision, fore region wider (Figs. 2C, 3C)... Minablatta Rehn 3 Ratio between total body length and width $\approx 2: 1$; pronotum strongly gibbous; yellow, darker in the middle; dorsal microsculptures very short ending with a seta (Figs. 2D, 3D). Hiereoblatta Rehn - Ratio between total body length and width $\approx 1,7: 1$; pronotum hind margin forming $120^{\circ}$ angle $\ldots 4$ 4 Very flat, smooth, specially dorsally, with dark spots very visible in the dorsal surface from the pronotum to the fore region of the supra-anal plate, dorsal microsculptures very slender, making like a row of columns along the hind margins of pronotum and tergites (Figs. 2B, 3B)... Petasodes Saussure - Not very flat, dorsal surface of pronotum and tergites very rough covered by thorn-like cuticular microsculptures much more abundant near the hind margins (Figs. 2A, 3A)... Monastria Saussure 
150 Monastria Saussure, 1864a: 255, 1864b: 348; Kirby, 1904: 161; Princis, 1958: 75, Princis, 1963: 141.

151 Tarraga Walker, 1868: 16; Princis, 1963: 141 (as syn. of M. biguttata).

152

153 Type Species. Monastria biguttata (Thunberg, 1826) = Blatta biguttata Thunberg, 1826 (Fig. 4).

155 Diagnosis. Dark brown to black or shiny black cockroaches with pronotum having orange or ochre 156 spots in the middle. Evident sexual dimorphism, males elongated with wings extending beyond the 157 apex of cerci, and females brachypterous. Male pronotum with a characteristic pentagonal transverse 158 shape, lateral margins with sharp angles and a conspicuous small notch. Female pronotum 159 subtriangular with a depression near the margins, and lateral margins with conspicuous small notch or 160 spine. Coxae covered by setae in males, antero-ventral femora margins with spines of equal size.

161 Apical and genicular spines absent. First meta tarsomere of hind leg short and without spines, claws 162 symmetrical and simple, small arolia. L1 present as a single sclerite, its posterior margin almost 163 entirely covered by a crown of small spines, closely packed.

165 Generic description. Male (Fig. 5). Medium size (40-55 mm). Head subtriangular; eyes extending 166 antero-laterally beyond the antennal socket (Fig. 5C); interocular space narrow at its closest distance 167 and smaller than the one between the antennal sockets $(0.8-1.8 \mathrm{~mm})$. Antennae not surpassing the 168 apex of the tegmina, filiform and setose from the eighth flagellar segment. First flagellar segment 169 larger than the pedicel. Maxillary palps with the fifth segment more dilated and very tomentose.

170 Pronotum pentagonal with fore margin strongly arcuate, hind margin nearly very weakly arcuate, and 171 a specific black coloration pattern in the central region (Fig. 5B). Tegmina developed, extending 172 beyond the apex of cerci; marginal field short and slightly concave; scapular field tapering toward 173 apex; mid-field discoidal, extended apically, slightly angular along veins; subcostal vein with a carina 174 on its ventral surface, anal veins reaching the posterior border (Fig. 5A). Wing marginal field narrow, 175 subcostal vein reaching basal third of scapular field; cubital vein with numerous complete and few 176 incomplete veins; apical triangle absent. Setae in the dorsal region of the three thoracic segments and 177 in the first abdominal segment. Fore-femora ventro-anterior margins with 16 spines of the same size

178 arranged side by side, the last one near the apex directed outward, ventro-posterior margins with 3 179 spines distributed in uniform spaces along the fore-femora and the last one near the apex. Middle legs 180 ventro-anterior margins of with 3 or 4 spines, the last one close to the apex. Tarsomeres 1-4 with 181 pulvilli, the pulvillus of the first metatarsomere very long, covering more than half of the length of 182 metatarsomere; tarsal claws simple and symmetrical; small arolium present. First abdominal tergite 183 unspecialized. Supra-anal plate quadrangular, posterior border bilobated with a strong median incision. 184 Cerci short, cylindrical, with different coloration in the last segments. Subgenital plate slightly 185 asymmetric. Internally, attached to this plate, a membranous pouch with genital sclerites L1 (Figs. 5G, 
H), L2d (Figs. 5F, I) and R (right phallomere) (Figs. 5D, E). Sclerite L1 long and thin with the apical

187 part distinct, quite sclerotized and the left branch tooth-shaped; central portion with a small posteriror

188

189

190

191

192

193

194

195

196

197

198

199

200

201

202

203

204

205

206

207

208

209

210

211

212

213

214

215

216

217

218 projection and a branch on the right side directed upwards; apical region with a crown of sclerotized spines. Sclerite L2d hook-shaped, like in most species of Ectobiidae and Blaberidae. Distal area elongated with subapical notch. Sclerite R (right phallomere) formed by sclerotized regions R2, R3d, R3v and N (Figs. 5D). Sclerite R2 ("cleft") curved, deep and directed upward. Sclerite R3d wide and elongated longitudinally with a dorsal part reduced and a large ventral one in the distal region. Sclerite $\mathrm{R} 3 \mathrm{v}$ with a flattened and inverted $\mathrm{v}$ shape in ventral view; rounded anterior lateral apex, and short caudal branch (Fig. 5E).

Female (Figs. 4, 6A-D). Species of medium size (30-45 mm). Head rounded, with wide interocular space measuring $1 / 2$ the distance between the antennal sockets $(2.0-3.1 \mathrm{~mm})$. Eyes reniform with straight interocular margin. Antennae reaching the apex of the tegmina, filiform and setose from the eighth flagellar segment. Ocelli developed and deflected. Front broad and frontal suture with a cuticular invagination (Fig. 6D). Pronotum subtriangular with anterior region rounded and slightly concave near the margins, dorsal region rough with striae, lateral angles rounded ending in a corner, posterior margin slightly curved in the median region (Fig. 6B). Brachypterous. Tegmina truncated with a marked curvature towards the interior and not extending further than the second abdominal tergite; wings much shorter and undeveloped (Fig. 6A). Legs short and robust. Fore femora ventroanterior margins with 13 spines of the same size, the last one close to the apex; ventro-posterior margins with 4 spines, the last one close to the apex. Middle legs ventro-anterior margins with 4 spines, the last one close to the apex. Supra-anal plate bilobed with a small median incision, each lobe with slightly rounded lateral and straight posterior margin (Fig. 6C). Tergites with slightly rounded lateral angles (Fig. 6A).

Juvenile stages. Juveniles of both sexes are oval, almost rectangular with a body length and width ratio $\approx 1,7: 1$. Beige to light brown, uniformly colored, the dorsal surface of pronotum and tergites is very rough (Fig. 7), covered by thorn-like cuticular microsculptures, often more abundant at their hind margins. (Fig. 3A). Head, eyes, antennae, legs, supra-anal and subgenital plate very similar to those in adults (Fig. 7E).

Habitat and Behavior. Specimens of Monastria were observed in a large array of forest ecosystems, ranging from semi-deciduous forests at the Northeast to the humid montane forests in the central region and the Araucaria forests in the South. All specimens were observed and collected in the forest understory on the underside of dead trunks of various sizes, as it was described in details for $M$. biguttata (Pellens \& Grandcolas, 2003). Very often found grasping on the underside of the bark or the wood of dead trunks, immediately freezing when disturbed. The body of the juveniles are covered by 
223 fine particles of the substrate where they are found, which are attached to the tegument structures (Fig.

224 7). Adult males have never been seen flying, even if they look able to do so with their large and

225 mobile wings. As any blaberid species, they are ovoviviparous, the females retract the large oothecae

226 in the brood sac. Juvenile stages are often observed in groups that remain near each other until

227 adulthood.

Key to the species of the genus Monastria

1 Female pronotum with acute lateral angles; absence of notch or spines (Fig. 9A, B) ... M. angulata

\section{Saussure}

233 - Male and Female pronotum with sharp or rounded lateral angles; with notch or spines ... 2

2342 Female tegmina long, reaching the fifth abdominal tergite; hind margins curved and rounded. Male

235 with L1 sclerite with lateral branch curved, rounded and with some small spines ....3

236 - Female tegmina short, not extending further than the fourth abdominal tergite; hind margin truncated 237 or with a curvature. Male with L1 sclerite with lateral branch slightly curved forward, with the aspect 238 of a big sharp tooth ....4

$2393 \mathrm{~L} 1$ sclerite with lateral branch curved, rounded and smooth with some small spines; R3d sclerite 240 with a clear prominence like a tooth in ventral view (Fig. 14)....M. kaingangue sp. n.

241 - L1 sclerite with lateral branch curved and rounded with large spines directed downwards (Fig. 8); R2

242 sclerite shorter and forming a right angle ....M. similis (Serville)

2434 Male L1 sclerite with a big lateral dilatation and an edge in the posterior median region (Fig. 10).

244 Female supra-anal plate with straight posterolateral angles...M. cabocla sp. n.

245 - Male L1 sclerite without a big lateral dilatation and an edge in the median region. Female, supra-anal 246 plate posterolateral angles rounded...5

2475 L1 sclerite slightly concave region with irregular distal margins with grooves (Fig. 11). Female frons 248 with a prominence ....M. itubera sp. n.

249 - L1 sclerite without slightly concave region and irregular distal margins with grooves. Female frons 250 flat. ..6

$2516 \mathrm{~L} 1$ sclerite with lateral branch slightly curved with some spines reaching the crown of spines at the 252 posterior region (Fig. 13) ....... itabuna sp. n.

253 - L1 sclerite without lateral branch with some spines reaching the crown of spines in the posterior 254 region ...7

$2557 \mathrm{~L} 1$ sclerite with a sharp dorsal protuberance and with a projection in the right side turned forward;

256 L2d sclerite, hook with internal ventral margin concave (Fig. 5).... M. biguttata (Thunberg)

257 - L1 sclerite with a roughly triangular spear-shaped apical region, hind margin with a large non258 sclerotized projection. L2d sclerite, hook with internal ventral margin strongly convex (Fig. 16)...M. 
Species

262

263

\section{Monastria biguttata (Thunberg, 1826)}

264 Male - Figure 5.

265 Female - Figures 4; 6A-D.

266

267

Blatta biguttata Thunberg, 1826: 276; Scudder, 1868: 13.

268 Blaberus biguttata Serville, 1831.

269 Monachoda biguttata Burmeister, 1838: 514; Brunner v. W, 1865: 365; Saussure, 1870: 120; Finot,

270 1897: 207

271 Blabera biguttata Serville, 1839: 80.

272 Monastria biguttata Saussure, 1864a: 256; Saussure, 1864b: 348; Walker, 1868: 11; Kirby, 1904: 161;

273 Shelford, 1907-1908: 469; Rehn, 1911: 248, Rehn, 1913: 282, Rehn, 1915: 275, Rehn, 1920: 217;

274 Hebard, 1921: 246; Princis, 1949: 66; Princis, 1958: 75, Princis, 1963: 141.

275 Blabera nigripennis Walker, 1868: 6; Finot, 1897: 210; Princis, 1963: 142 (as syn. of M. biguttata).

276 Tarraga guttiventris Walker, 1868: 16; Finot, 1897: 213; Princis, 1963: 142 (as syn. of M. biguttata).

277 Blabera monstrosa Stâl, 1855: 351; Kirby, 1904: 165; Princis, 1963: 142 (as syn. of M. biguttata).

278 Blabera mostruosa Sjostedt, 1933: 10; Princis, 1963: 142 (as syn. of M. biguttata, lapsus calami).

279

280 Examined material. Brazil - Rio de Janeiro: 7m\# 3f\# Niterói. "Parque da Cidade", 225m,

$28122^{\circ} 55^{\prime} 42^{\prime}$ S, $43^{\circ} 05^{\prime} 10$ ”W, 500m de la plage du saco de São Francisco, Forêt semp. humide, 21 IX

282 2009, R. Pellens \& P. Grandcolas rec. (MNHN). $1 \mathrm{m \# \#} \mathrm{Angra} \mathrm{dos} \mathrm{Reis,} \mathrm{Ilha} \mathrm{Grande,} \mathrm{"Sentier}$

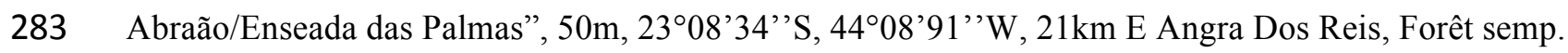

284 humide, 07 VIII 2007, R. Pellens \& P. Grandcolas rec. (MNHN). 1m\#, 1f\# Visconde de Mauá, “Apa

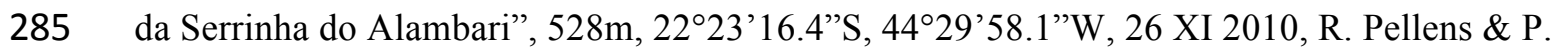

286 Grandcolas rec. (MNHN). 1m\# Montagnes des Orgues, Prov. de Rio de Janeiro, Environs de la Tijuca,

287 E. R. Wagner - 1902 (MNHN). 1m\# Floresta da Tijuca, V 1966, M. Alvarenga col. (MZUSP). $1 \mathrm{f \#}$

288 "Tejuca", I 1857, coll. H. Clark (NHM). Espirito Santo: 2m\#, 3f\# Res de Linhares, "CVRD",

$28919^{\circ} 09^{\prime} 10.2$ ”S, 40¹1’07.8”W, 19 X 1999, 40km NNE Linhares, Forêt semi-décidue, "Mata Alta”, R.

290 Pellens \& P. Grandcolas rec. (MNHN). 1m\# Linhares, Fragment "Sitio São Pedro", 1909'14.2”S,

$29140^{\circ} 11^{\prime 3} 4.3$ ”W, 11 VII 2005, 40km NNE Linhares, Forêt semi-décidue, R. Pellens \& P. Grandcolas

292 rec. (MNHN). Santa Teresa, Est. Biol. Santa Lucia, 810m, 1958'18.5”S, 40³2’07.6”W, 6 - 9 IV

293 2001, Malaise, ponto 3 trilha, C. O. Azevedo \& equipe col. (MZUSP). Without locality: 3f\#

294 (America Meridionale) (MHNG). 2m\#, 6f\# (NHM). 
Diagnosis. This species is characterized by the presence of two additional cuticular depressions in the frons near the clypeus. L1 sclerite with lateral branch slightly curved forward, with the aspect of a big sharp tooth, and with spines in the ventral region near the crown of spines; a pointy medial region with a projection in the right side turned forward. $\mathrm{R} 2$ sclerite cleft very sclerotized, rounded at the side of $\mathrm{N}$ sclerite. $\mathrm{N}$ sclerite tiny in the dorsal region, and large and globular in the ventral one. R3d slightly curved dorsally and wider and straight in ventral view. R3v sclerite with a wide and rounded laterodistal region and a short and slightly narrow caudal branch.

Redescription. Male. Head subtriangular, with interocular space measuring approximately $1 / 5$ of the distance between the antennal sockets. Ocelli developed and slightly deflected. Frontal suture with a cuticular invagination. Two additional cuticular depressions in the frons near the clypeus (Fig. 5C). Pronotum transverse, pentagonal, dorsal surface rough with striae, fore margin rounded, lateral margins with sharp angles and round ends, hind margin nearly straight (Fig. 5B). Legs short and robust. Fore-femora ventro-anterior margins with 16 spines of the same size; ventro-posterior margins with 3 spines. Middle-legs ventro-anterior margins with 3 or 4 spines. Supra-anal plate quadrangular with setae on the surface, hind margin straight and slightly rounded laterally, bilobed with a strong invagination in the median portion. Subgenital plate asymmetrical with long styles, funneled in the apical region. L1. With the left side of the apical region with a lateral branch $(\mathrm{Lb})$ slightly curved forward, with the aspect of a big sharp tooth with spines near the crown of spines. The right side of the apical region with a pointy medial protuberance and a projection turned forward (Fig. 5G, H). L2d sclerite hook with a soft subconical and slightly narrow anterior region, a short apical sclerotized region, and a wide space connecting them. Apex internal cavity concave, short lateral-external margin and with a typical sub-apical notch (Fig. 5F, I). R2 sclerite cleft very sclerotized, rounded and curved inward with the apex directed upward (Fig. 5D). Sclerite $\mathrm{N}$ tiny in the dorsal region, and large and globular in the ventral one. R3d slightly curved dorsally and wider and straight in ventral view. Sclerite R3v with a flattened and inverted $\mathrm{v}$ shape in ventral view; rounded anterior lateral apex, and short caudal branch. (Fig. 5D, E).

325 Female. Head rounded, with wide interocular space measuring 1/2 the distance between the antennal sockets. Eyes with slightly inclined interocular margins. Ocelli developed and deflected. Front broad and frontal suture with a cuticular invagination (Fig. 6D). Pronotum subtriangular with anterior region rounded and slightly concave near the margins, dorsal region rough with striae, lateral angles rounded ending in a corner, hind margin slightly curved in the median region (Fig. 6B). Tegmina with anterior margin slightly triangular; hind margin truncated with a marked curvature inside; very short and not extending further than the second abdominal tergite (Fig. 6A). Legs short and robust. Fore femora 
legs ventro-anterior margins with 4 spines. Supra-anal plate bilobed with a small median incision, each lobe with a slightly rounded lateral margin and a straight posterior margin (Fig. 6C). Tergites with straight lateral angles (Fig. 6A).

Measurements (mm). m\#: Body length 51.70; pronotum length $12.36 \times 17.35$ maximum width; tegmen length $42.55 \times 15.90$ width; interocular width 1.0 ; interantennal width between sockets 5.5 f\#: Body length 38.50 ; pronotum length $11.20 \times 17.55$ maximum width ; tegmen length $10.00 \times 11.25$ width; interocular width 2.3; interantennal width between sockets 5.0 .

Coloration. m\#: General coloration brown (Fig. 5A). Pronotum dark brown with anterior margin buff brown; central disk pale brown with scattered black marks (Fig. 5B). Head dark brown-black; clypeus and labrum amber. Antennae with basal segments brown pigmented and apical segments pale brown. Ocelli pale brown (Fig. 5C). Legs and spines dark brown; tarsal claws, pulvilli and arolia amber. Tegmina and abdomen following general coloration of body (Fig. 5A) but with dark brown tergites and sternites hind margins.

Distribution. Brazil (Rio de Janeiro, Espirito Santo). See Fig. 17 for details.

\section{Monastria similis (Serville, 1838)}

Male - Figure 8.

Female - Figure 6E-H.

Blabera similis Serville, 1839: 81.

Monastria similis Saussure, 1864a: 256; Walker, 1868: 11; Scudder, 1868: 54; Kirby, 1904: 161; Princis, 1958: 75, Princis, 1963: 142.

Monachoda similis Brunner v. W, 1865: 367; Saussure, 1870: 120; Finot, 1897: 207.

Monastria flavomarginata Princis, 1946: 162, Princis, 1963: 142 (as syn. of M. similis).

Examined material. Brazil - Paraná: 1f\# Aurora do Iguaçu, "Fazenda Dona Iolanda", 260m, 2523’047’S, 5407’048”'W, 20km NE São Miguel do Iguaçu, Fragment=60ha, Forêt semp. Humide, 18 XI 2008, Jour, coll. R. Pellens \& P. Grandcolas (MNHN). 2m\#, 1f\# Foz do Iguaçu, "Fazenda John Keller”, 220 m, 25³4'9.14”S, 54²6’7.41”W, $1 \mathrm{~km}$ Parc National do Iguaçu, Forêt semp. humide, 20 XI 2008, R. Pellens \& P. Grandcolas rec. (MNHN). Santa Catarina: 1m\# Blumenau, VI 1919, coll. Luderm? (MZUSP). 3m\#, 2f\# Campo Alegre, “Ilha, Fazenda Sr. Egon”, 830m, 26¹0’29’'S, 49¹6’22' W, 1km Campo Alegre, 14 VIII 2007, Forêt d'Araucaria, R. Pellens \& P. Grandcolas rec. (MNHN). 1f\# Campo Alegre, “Fazenda Sr. Gilson”, 853m, 26¹2’6.61”S, 49¹8’4.58”W, 5km W Campo Alegre, Forêt d'Araucaria, 15 VIII 2007, R. Pellens \& P. Grandcolas rec. (MNHN). 1f\# 
Florianopolis, “Chemin Mirante. route Lagoa da Conceiçao", 295m, 27³5’5.05”S, 48²8’6.08”W,

371 Forêt semp. humide, 01 XII 2008, R. Pellens \& P. Grandcolas rec. (MNHN). 2f\# Joinville, “Alto da

372 Serra Dona Franscisca”, 755m, 26¹1'882” S, 4903’144” W, 35km NW Joinville, Forêt semp.

373 humide, III 2007, R. Pellens \& P. Grandcolas rec. (MNHN). 1m\# 4f\# Lages, Brunner d. w. (MHNG).

$3741 \mathrm{~m} \# 1 \mathrm{f} \#$ Rio Capivary, 1888, H. Fruhstorfer (MHNG). Rio Grande do Sul: 2m\# Lhering, (MNHG).

375 São Paulo: 1m\# Poa, 13 IV 1963, Rabello col. (MZUSP). 1m\# Salesópolis, "Estação biológica de

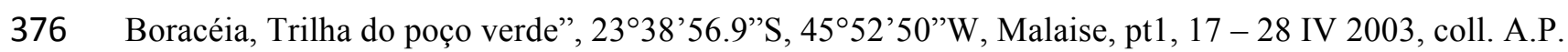

377 Aguiar \& F.M. Rodrigues (MZUSP). 1m\# Salesópolis, "Est. biológica de Boracéia”, 850m, (MZUSP).

378 Paraguay: 1f\# Asunción, sept.1922-apl.1923, E.G.Kent, B.M. 1925 - 262 (NHM). 1m\#, Carlos

379 Pfanni (MHNG) Without locality: 1m\# Brésilien, H. Fruhstorfer, 1903 - 321(NHM). 2f\# (NHM).

$3801 \mathrm{~m} \#$ (America Meridionale/Colombie?), D. Ruhl (MHNG). 1m\# coll. Pantel, co-type (MNHN).

382 Diagnosis. Male - The apical left side of L1 with a short rounded lateral branch turned downwards

383 with strong spines near the crown of spines and a wide region slightly concave with a slight curvature

384 ending in a small projection towards the front on the right side. L2d sclerite hook with internal cavity

385 strongly concave, external lateral margin very near the very narrow sub-apical notch. R2 sclerite

386 shorter and forming a right angle. Sclerite $\mathrm{N}$ reduced in the dorsal region and a wide and globular

387 ventral surface. R3d slightly curved dorsally and wider and straight in ventral view. R3v small,

388 triangular, with a short and slightly quadrangular latero-distal region; caudal branch short with a finger

389 shaped apex.

390

391 Redescription. Male. Head subtriangular, with interocular space measuring nearly $1 / 3$ of the distance

392 between the antennal sockets. Ocelli developed and slightly deflected. Frontal suture with a slight

393 cuticular invagination (Fig. 8C). Pronotum transverse, pentagonal, dorsal surface rough with deep

394 striae, anterior margin rounded, lateral margins with sharp angles and round ends, hind margin nearly

395 straight (Fig. 8B). Tegmina with orange lateral margins in the first half of its length (Fig. 8A). Legs

396 short and robust. Fore-femora ventro-anterior margins with 21 or 22 spines decreasing in size from

397 basal to apical; ventro-posterior margins with 3 long and 2 slightly smaller spines. Middle legs ventro-

398 anterior margins with 10 spines. Supra-anal plate quadrangular with setae on the surface, hind margin

399 straight and slightly rounded laterally, bilobed with an invagination in the median portion. Subgenital

400 plate asymmetrical with long styles, funneled in the apical region. L1 sclerite with apical region with

401 two distinct parts: a short, rounded lateral branch turned downwards, with strong spines near the

402 crown of spines of the posterior region; a wide region slightly concave with a slight curvature ending

403 in a small projection towards the front on the right (Fig. 8H, I). L2d sclerite hook with anterior region

404 subconical and slightly wide and a short apical region; internal cavity strongly concave, external

405 lateral margin very near the very narrow sub-apical notch (Fig. 8F, G). R2 sclerite cleft curved inwards

406 with the apex very sclerotized and directed upwards; shorter and forming a right angle (Fig. 8D). 
Sclerite $\mathrm{N}$ dorsal region reduced, ventral surface wide and globular. R3d slightly curved dorsally and wider and straight in ventral view. R3v small, triangular, with a short and slightly quadrangular laterodistal region; caudal branch short with a finger shaped apex (Fig. 8D, E).

Female. Head rounded, with wide interocular space measuring 1/2 of the distance between the antennal sockets. Eyes with straight interocular margin. Ocelli small and located on the area slightly deflected above the antennal socket. Frons broad and flattened, frontal suture with a small cuticular depression. Clypeus distal half larger and yellow transparent (Fig. 6H). Pronotum subtriangular with anterior region rounded and slightly concave near the margins, dorsal region rough with deep striae, lateral angles rounded ending in a corner, hind margin slightly curved in the median region (Fig. 6F). Tegmina with a rounded anterior margin, orange lateral margin, and rounded and curved hind margin. Long, reaching the fifth abdominal tergite (Fig. 6E). Legs short and robust. Fore-femora ventroanterior margins with 21 or 19 long spines of the same size, ventro-posterior margins with 5 spines. Middle legs ventro-anterior margins with 5 spines. Supra-anal plate bilobed with a small median notch, each lobe with a slightly rounded lateral and a straight hind margin (Fig. 6G). Tergites with rounded lateral angles (Fig. 6E).

Measurements (mm). m\#: Body length 49.35; pronotum length $10.95 \times 16.80$ maximum width; tegmen length $39.75 \times 15.45$ width; interocular width 1.6 ; interantennal width between sockets 4.6. $\mathrm{f} \#$ : Body length 36.65 ; pronotum length $11.35 \times 16.90$ maximum width; tegmen length $16.50 \times 11.00$ width; interocular width 2.6; interantennal width between sockets 5.6.

Coloration. m\#: General coloration brown (Fig. 8A). Pronotum dark brown with anterior margin buff brown; central disk orange with large dark brown mark (Fig. 8B). Head dark burnt umber; clypeus amber and labrum orange. Antennae with basal segments brown pigmented and apical segments pale brown. Ocelli white (Fig. 8C). Legs brown and spines with brown base and dark brown apex; pulvilli yellowish white; tarsal claws and arolia amber. Tegmina with orange lateral margins (Fig. 8A).

Abdomen following general coloration of body but with brown tergites and sternites hind margins.

Distribution. Brazil (São Paulo, Paraná, Santa Catarina, Rio Grande do Sul), Paraguay (Asunción). See Fig. 17 for details.

\section{Monastria angulata Saussure, 1864a}

Figure 9A-D.

Monastria angulata Saussure, 1864a: 257; Walker, 1868: 11; Kirby, 1904: 161; Princis, 1963: 142. Monachoda angulata Saussure, 1870: 120; Finot, 1897: 207. 
445 Examined material. Syntype f\#. Brazil, Bahia. (MHNG)

447 Diagnosis. Pronotum triangular, with rounded anterior region slightly concave near the margins,

448 inconspicuous dorsal roughness and striae. Lateral angles pointy, without corners, hind margin slightly

449 curved in the median region. Tegmina anterior angle nearly square, hind margin truncated with a

450 marked curvature towards the medial margin. $\mathrm{CuP}$ vein ending at the half of the hind margin. Supra-

451 anal plate bilobed, lateral margins of each lobe very rounded.

452

453 Redescription. Female. Head subtriangular, with wide interocular space measuring $1 / 2$ of the

454 distance between the antennal sockets. Eyes with straight interocular margin. Ocelli developed and

455 deflected. Front broad and frontal suture with a small cuticular invagination (Fig. 9D). Pronotum

456 triangular, with anterior region rounded and slightly concave near the margins; dorsal roughness and

457 striae inconspicuous. Lateral angles pointy, without corners, hind margin slightly curved in the median

458 region (Fig. 9B). Tegmina very short and not extending further than the second abdominal tergite;

459 anterior angle nearly square, hind margin truncated with a marked curvature towards the medial

460 region. CuP vein ending at the half of the hind margin (Fig. 9A). Legs short and robust. Fore-femora

461 ventro-anterior margins with 16 or 17 spines of the same size, ventro-posterior margins with 4 spines.

462 Middle legs ventro-anterior margins with 4 spines. Supra-anal plate bilobed with a small median

463 notch, each lobe with a very rounded lateral margin and a slightly straight hind margin (Fig. 9C).

464 Tergites with quadrangular lateral angles (Fig. 9A).

466 Male. Unknown

468 Measurements (mm). Syntype \#f: Body length 30.70; pronotum length $10.00 \times 17.57$ maximum

469 width ; tegmen length $9.80 \times 12.20$ width; interocular width 2.6 ; interantennal width between sockets

$470 \quad 5.6$.

471

472 Coloration. Syntype \#f: General coloration burnt umber (Fig. 9A). Pronotum burnt umber with a

473 anterior margin ochre; central disk yellowish brown with scattered dark brown marks (Fig. 9B). Head

474 burnt umber and clypeus and labrum dark brown (Fig. 9D). Antennae with segments yellowish brown.

475 Ocelli ochre. Legs and spines dark brown; tarsal claws, pulvilli and arolia yellowish brown. Tegmina

476 with anal field burnt umber and marginal field brown; abdomen following general coloration of body

477 but with tergites and sternites hind margins dark brown (Fig. 9A). Supra-anal plate burnt umber (Fig.

$4789 \mathrm{C})$.

479

480 Distribution. Brazil (Bahia). 
482 Monastria cabocla Tarli, Grandcolas \& Pellens sp. n.

483 Male - Figure 10.

484 Female - Figure 9E-H.

485

486 Type material. Holotype \#m, Brazil, Sergipe, Santo Amaro das Brotas, "Gravata” 13 I 1979 (MZUSP).

487 Allotype \#f and Paratypes 1\#m, 2\#f, same data as holotype (MZUSP). 1\#f Sergipe, Santo Amaro das

488 Brotas, "871”, 1046'51.2"S, 3703'22.8"W (coordinates assigned à posteriori) (MNRJ).

489

490 Diagnosis. Frons depressed below the antennal sockets and prominent above the ocelli. Ocelli

491 positioned laterally. Pronotum dorsal surface slightly rough and striated, with two quite evident lobes

492 with plain surface, and a wider central lobe covering the head. Short lateral margins with sharp angle

493 and a conspicuous small spine. Legs longer and less robust. L1 sclerite with a lateral branch little

494 sclerotized slightly curved downwards, smooth and with only a small spine and a region with a big

495 lateral dilatation and an edge in the posterior median region with a lateral projection turned forward.

496 Crown with a smaller number of sclerotized spines in the posterior region. L2d sclerite, hook with

497 subconical and very wide anterior region. Sclerite $\mathrm{N}$ triangular on the dorsal region. R3d with a slight

498 depression in the dorsal median region.

499

500 Description. Male. Head subtriangular, with interocular space measuring 1/4 of the distance between

501 the antennal sockets. Frons with a depression below the antennal sockets and prominent above the

502 ocelli. Frontal suture localized in a deep cuticular invagination, ocelli developed and positioned

503 laterally (Fig. 10C). Pronotum transverse, pentagonal, dorsal surface slightly rough and striated, with

504 two quite evident lobes with plain surface and a wider central lobe covering the head, anterior margin

505 rounded, short lateral margins with sharp angle and a conspicuous small spine, hind margin nearly

506 straight (Fig. 10B). Legs longer than in other species and less robust. Fore-femora ventro-anterior

507 margins with 24 or 22 spines slightly decreasing in size from basal to apical; ventro-posterior margins

508 with 5 spines. Middle legs ventro-anterior margins with 5 spines. Supra-anal plate quadrangular with

509 setae on the surface, hind margin straight and slightly rounded laterally, bilobed, lobes very narrow

510 and with a strong invagination in the median portion. Subgenital plate asymmetrical with long styles,

511 funneled in the apical region. L1 sclerite apical region with two distinct parts: a lateral branch little

512 sclerotized slightly curved downwards, smooth and with only a small spine, and a region with a big

513 lateral dilatation and an edge in the posterior median region with a lateral projection turned forward.

514 Crown with a smaller number of sclerotized spines. (Fig. 10G, H). L2d sclerite hook with subconical

515 and very wide anterior region, a median apical region, and a narrow space connecting them. Apex

516 internal cavity concave with short lateral external margin and narrow subapical notch (Fig. 10F, I). R2

517 sclerite cleft sclerotized, curved inward with a conic opening at its base and an apex directed upwards. 
518 Sclerite $\mathrm{N}$ triangular on the dorsal region (Fig. 10D) and with a small surface in the ventral one. R3d

519 with a slight depression in the dorsal median region and narrow in ventral view (Fig. 10D, E). R3v

520 sclerite with a long, rectangular and slightly wide latero-distal region, and quadrangular caudal branch

521 very near R3d (Fig. 10E).

522

523 Female (Allotype). Head rounded, with wide interocular space measuring 1/2 of the distance between

524 the antennal sockets. Eyes with curved interocular margin. Ocelli developed and deflected. Frons

525 broad, frontal suture with a large cuticular invagination (Fig. 9H). Pronotum subtriangular, dorsal

526 surface slightly rough and striated, with two quite evident lobes with plain surface, and a wider central

527 lobe covering the head; anterior margin rounded, lateral margins short with sharp angle and a

528 conspicuous small spine, hind margin nearly straight (Fig. 9F). Tegmina latero-anterior angle nearly

529 straight; lateral margin wider, and hind margin with a strong curvature near the radial vein; extends

530 further than the third abdominal tergite. CuP vein very marked (Fig. 9E). Legs short and robust. Fore-

531 femora ventro-anterior margins with 19 small spines of the same size, ventro-posterior margins with 4

532 spines. Middle legs ventro-anterior margins with 9 spines. Supra-anal plate bilobed with a median

533 incision, and each lobe with straight posterolateral angles (Fig. 9G).

534

535 Measurements $(\mathbf{m m})$. Holotype \#m: Body length 42.95; pronotum length $9.85 \times 15.70$ maximum

536 width; tegmen length $35.25 \times 13.45$ width; interocular width 0.9 ; interantennal width between sockets

537 3.6. Paratypes \#m: Body length 41.54; pronotum length $09.94 \times 15.20$ maximum width; tegmen length

$53831.36 \times 13.19$ width; interocular width 0.5 ; interantennal width between sockets 1.8 .

539 Allotype \#f: Body length 41.60 ; pronotum length $13.20 \times 20.15$ maximum width ; tegmen length

$54016.05 \times 14.50$ width; interocular width 2.9 ; interantennal width between sockets 6.0. Paratype \#f :

541 Body length 40.82 - 41.96; pronotum length $12.15-12.86 \times 20.12-19.91$ maximum width; tegmen

542 length $14.53-15.06 \times 12.48$ - 13.76 width; interocular width $1.3-1.4$; interantennal width between

543 sockets $2.4-2.5$.

544

545

546 Coloration. Holotype \#m: General coloration sienna brown (Fig. 10A). Pronotum sienna brown with a

547 brown anterior margin; central disk seal brown with scattered dark marks (Fig. 10B). Head reddish

548 brown; clypeus and labrum amber. Antennae with basal segments dark brown pigmented and apical

549 segments brown. Ocelli pale brown (Fig. 10C). Legs and spines dark brown; tarsal claws, pulvilli and

550 arolia whitish brown. Tegmina sienna brown with marginal and scapular field with a buff brown part

551 (Fig. 10A). Abdomen following general coloration of body.

552

553 Etymology. A term from the Tupi meaning taken out of the forest. Here it refers to the habitat and the

554 color patterns of this species. 
556 Distribution. Brazil (Sergipe). See Fig. 17 for details.

\section{Monastria itubera Tarli, Grandcolas \& Pellens sp. n.}

559 Male - Figure 11.

560 Female - Figure 12A-D.

Type material. Holotype \#m, Brazil, Bahia, Itubera, "Reserva ecológica Michelin",92 - 383m,

$56313^{\circ} 48^{\prime} 4.62^{\prime}$ 'S, 39¹0’23.2' 'W. 100km N Itabuna, Forêt semi-décidue, 28 VIII 2007, R. Pellens \& P.

564 Grandcolas rec. (MZUSP). Allotype \#f, and Paratype 1 \#m, same data as holotype (MNHN).

566 Diagnosis. This species is characterized by having triangular head. L1 sclerite lateral branch slightly

567 curved with some spines turned downwards and a slightly concave region with irregular distal margins

568 with grooves ending in a long projection towards the front; L2d sclerite hook with subconical slightly

569 narrow anterior region, short apical region, and a large space connecting them. Apex internal cavity

570 concave with small lateral external margin and narrow subapical notch with pointy margin; R2 sclerite

571 cleft curved inward with a conic opening at its base and with a sclerotized apex directed upwards.

572 Sclerite $\mathrm{N}$ wider on the dorsal region, narrow and small in ventral surface. R3d narrow in the right and

573 rectangular in the left when in dorsal view. R3v sclerite small, subtriangular, with rounded latero-

574 distal end.

576 Description. Male. Head triangular, with narrow interocular space measuring approximately $1 / 6$ of 577 the distance between the antennal sockets. Ocelli developed and slightly deflected; frontal suture with 578 a strong cuticular invagination (Fig. 11C). Pronotum transverse, pentagonal, dorsal surface rough with deep striae; anterior margin rounded; lateral margins with sharp angles, round ends and a conspicuous small protuberance; hind margin nearly straight (Fig. 11B). Legs short and robust. Fore-femora ventroanterior margins with 20 or 18 spines of the same size; ventro-posterior margins with 4 small spines.

582 Middle-legs ventro-anterior margins with 5 or 4 large spines. Supra-anal plate quadrangular with setae on the surface, hind margin straight and slightly rounded laterally, bilobed with a slight invagination in the median portion. Subgenital plate asymmetrical with long styli, left funneled in the apical region, right with same caliper all along. L1 sclerite apical region with two distinct parts, a lateral branch slightly curved with some spines turned downwards and the right branch slightly concave region with irregular distal margins with grooves ending in a long projection towards the front. Crown with less robust spines in the posterior region (Fig. 11H, I). L2d sclerite, hook with subconical slightly narrow anterior region and short apical region, with a large space connecting them. Apex internal cavity concave with small lateral external margin and narrow subapical notch with pointy margin (Fig. 11F, 
592

593

594

595

596

597

598

599

600

601

602

603

604

605

606

607

608

609

610

611

612

613

614

615

616

617

618

619

620

621

622

623

624

625

626

627

628

directed upwards (Fig. 11D). Sclerite $\mathrm{N}$ wider and near of $\mathrm{R} 2$ on the dorsal region, and a narrow and small ventral surface. R3d narrow in the proximity of R2, and wider and rectangular in the distal region when in ventral view (Fig. 11D, E). R3v sclerite small, subtriangular, with rounded latero-distal end (Fig. 11E).

Female (Allotype). Head rounded, with interocular space measuring approximately $1 / 3$ of the distance between the antennal sockets. Eyes reniform with rounded interocular margin. Ocelli developed and deflected. Concavity between eyes and ocelli reaching the frontal suture. Frons with a prominence (Fig. 12D). Pronotum subtriangular, anterior region rounded with a depression near the margins; dorsal surface rough with deep striae, presence of small spine at the end of lateral region, hind margin nearly straight (Fig. 12B). Tegmina with rounded lateral anterior angle, hind margin truncated with a slight curvature in the region of radial vein and merging to the $\mathrm{CuP}$ vein at the end, not extending further than the second abdominal tergite (Fig. 12A). Legs short and robust. Fore-femora ventroanterior margins with 21 or 20 spines of the same size, ventro-posterior margins with 4 spines. Middle-legs ventro-anterior margin with 8 spines, plus one near the apex. Supra-anal plate bilobed with a median incision and each lobe slightly rounded (Fig. 12C).

Measurements (mm). Holotype \#m: Body length 52.98; pronotum length $12.61 \times 18.49$ maximum width; tegmen length $42.22 \times 15.43$ width; interocular width 0.4 ; interantennal width between sockets 2.6. Paratype \#m: Body length 40.98; pronotum length $09.21 \times 15.14$ maximum width; tegmen length $31.22 \times 14.31$ width; interocular width 0.2 ; interantennal width between sockets 1.8 .

Allotype \#f: Body length 35.79; pronotum length $9.70 \times 17.05$ maximum width; tegmen length $8.90 \times$ 11.15 width; interocular width 1.5 ; interantennal width between sockets 4.5 .

Coloration. Holotype \#m: General coloration brown (Fig. 11A). Pronotum brown with the anterior margin pale brown; central disk pale brown with scattered black marks (Fig. 11 B). Head dark brown/black; clypeus and labrum brown. Antennae with basal segments dark pigmented and apical segments whitish yellow. Ocelli light brown (Fig. 11C). Legs dark brown. Spines and tarsal claws brown, pulvilli and arolia pale brown. Tegmina and abdomen following general coloration of body, but with tergites and sternites dark hind margins (Fig. 11A).

Etymology. The specific name refers to the type locality Itubera, state of Bahia, northeast Brazil

Distribution. Brazil (Bahia). See Fig. 17 for details.

\section{Monastria itabuna Tarli, Grandcolas \& Pellens sp. n.}


630 Female - Figure 12E-H.

632 Type material. Holotype \#m, Brazil, Bahia, Itabuna. CEPLAC, Matinha. 14²46'20' 'S, 39²13'18' 'W.

633 Elevation 46m, 11 V 2007, J. A. Rafael \& F. F. Xavier F (INPA). Allotype \#f, and 1 Paratype \#m, 634 same data as holotype (INPA).

636 Diagnosis. This species is characterized by having L1 sclerite with apical region having a lateral

637 branch slightly curved with some spines that contact the crown in the posterior region. L2d sclerite,

638 hook with short apical region, internal margin concave, lateral external margin strongly curved, with

639 large sub-apical notch. R2 sclerite cleft curved inward with the apex directed forward. Sclerite N

640 smaller in the dorsal region and with a large rough ventral surface. R3d narrow near R2 in dorsal view

641 and wider, rectangular in the distal region in ventral view. R3v sclerite large, with quadrangular and

642 truncated latero-distal end. Caudal branch long, wide in the center and narrow in the apex.

643

644 Description. Male. Head subtriangular, with narrow interocular space measuring approximately 1/6 of 645 the distance between the antennal sockets. Ocelli developed and slightly deflected; frontal suture with 646 a strong cuticular invagination. Clypeus distal half narrower transversally and orange brown (Fig.

647 13C). Pronotum transverse, pentagonal, dorsal surface rough with striae; anterior margin rounded;

648 lateral margins slightly wider with sharp angles, round ends and a conspicuous small protuberance;

649 hind margin nearly straight (Fig. 13B). Legs short and robust. Fore-femora ventro-anterior margins

650 with 20 or 18 spines of the same size; ventro-posterior margins with 4 small spines. Middle-legs

651 ventro-anterior margins with 5 or 4 large spines. Supra-anal plate quadrangular with setae on the

652 surface, hind margin straight and slightly rounded laterally, bilobed with a slight invagination in the

653 median portion. Subgenital plate asymmetrical with long styles, left funneled in the apical region, right

654 with same caliper all along. L1 sclerite with apical region with two distinct parts, a lateral branch

655 slightly curved with some spines that contact the crown in the posterior region (Fig. 13G, H). L2d

656 sclerite, hook with short apical region, internal margin concave, lateral external margin strongly

657 curved, with large sub-apical notch (Fig. 13F, I). R2 sclerite cleft curved inward with the apex directed

658 forward (Fig. 13D). Sclerite N smaller in the dorsal region and with a large rough ventral surface. R3d

659 narrow near R2 in dorsal view and wider, rectangular in the distal region when in ventral view (Fig.

$66013 \mathrm{D}, \mathrm{E}) . \mathrm{R} 3 \mathrm{v}$ sclerite large, with quadrangular and truncated latero-distal end. Caudal branch long,

661 wide in the center and narrow in the apex (Fig. 13E).

662

663 Female (Allotype). Head rounded, with wide interocular space measuring 1/2 the distance between

664 the antennal sockets. Eyes with straight interocular margin. Ocelli developed and deflected. Frons

665 broad, frontal suture with a cuticular invagination (Fig. 12H). Pronotum subtriangular, fore region 
rounded and slightly concave near the margins, dorsal region rough with deep striae, lateral margins rounded ending in a small corner, hind margin slightly curved in the median region (Fig. 12F).

668 Tegmina with straight lateral anterior angle, hind margin truncated with a slight curvature in the region

669 of radial vein; not extending further than the second abdominal tergite and lateral margin orange all

670 along its extension (Fig. 12E). Legs short and robust. Fore-femora ventro-anterior margins with 19

671 small spines of the same size; ventro-posterior margins with 4 spines. Middle-legs ventro-anterior

672 margins with 9 spines. Supra-anal plate bilobed with a median incision and each lobe slightly rounded

673 (Fig. 12G). Tergites with nearly straight lateral angles (Fig. 12E).

674

675 Measurements $(\mathbf{m m})$. Holotype \#m: Body length 53.05; pronotum length $12.70 \times 19.37$ maximum

676 width; tegmen length $40.40 \times 15.55$ width; interocular width 0.9 ; interantennal width between sockets

677 2.7 . Paratype \#m: Body length 54.09; pronotum length $12.22 \times 21.02$ maximum width; tegmen length

$67843.12 \times 19.61$ width; interocular width 0.5 ; interantennal width between sockets 2.8 .

679 Allotype \#f: Body length 40.70; pronotum length $11.25 \times 19.80$ maximum width; tegmen length 12.30

$680 \times 13.00$ width; interocular width -3.0 ; interantennal width between sockets 5.7 .

681

682 Coloration. Holotype \#m: General coloration dark brown (Fig. 13A). Pronotum dark brown with the

683 anterior margin yellowish brown; central disk yellowish brown with scattered black marks (Fig. 13B).

684 Head dark brown; clypeus and labrum yellowish brown. Antennae with basal segments dark

685 pigmented and apical segments whitish yellow. Ocelli yellowish/pale brown (Fig. 13C). Legs and

686 spines brown; tarsal claws, pulvilli and arolia yellowish brown. Tegmina and abdomen following

687 general coloration of body but with tergites and sternites with brown posterior margin (Fig. 13A).

688

689 Etymology. The specific name refers to the type locality Itabuna, state of Bahia, northeast Brazil.

690

691 Distribution. Brazil (Bahia). See Fig. 17 for details.

692

693 Monastria kaingangue Tarli, Grandcolas \& Pellens sp. n.

694 Male - Figure 14.

695 Female - Figure 15.

696

697 Type material. Holotype \#m, Brazil, São Paulo, Campinas. "Pico das Cabras". 2254'23.9"S

$69846^{\circ} 49^{\prime} 34.4^{\prime \prime}$ W. 14 october 2014, coll. V. M. Ghirotto (MZUSP). Allotype: 1\#f, same data as holotype 699 (MZUSP).

700

701 Paratypes - Santa Catarina: 1\#m, Urubici, "Parque Nacional de São Joaquim, Vacas Gordas", 977m, 702 2808’44.4”S, 49³7’09.3”W, 22 X 2015, coll. R. Pellens (MNHN). 2m\#, 1f\#, São Bonifácio, Santo 
Amaro da Imperatriz, -27.830854 -48.964832, 09 X 2014, P. Grandcolas \& Vitor D. Tarli rec. (MNHN). São Paulo: 1\#m Bocaina, IV 1924, Luderm? “27” (MZUSP). 1\#m Bocaina, IV 1924, “29” (MZUSP). Rio Grande do Sul: 1\#m, 2\#f, Derrubadas, Parque Estadual do Turvo, 391m, -27.236413 53.979640, 05 X 2014, R. Pellens \& Vitor D. Tarli rec. (MNHN).

707

Diagnosis. This species is characterized by having two intercalated rows of spines in the ventroanterior margins of fore-femora; one row with 5 or 6 spines, and another with 32 or 33 spines of the same size. L1 sclerite with lateral branch curved, rounded and smooth with some small spines, and a curved region with grooves in its interior and a projection with a rounded end directed upwards at its right side. L2d sclerite hook with long apical region, and rounded curvature of the margin near the notch. R2 sclerite cleft curved inward with a wide and sclerotized apex directed forward. R3d with a clear prominence like a tooth in ventral view. R3v sclerite with quadrangular and truncated laterodistal region, and caudal branch near the tooth from R3d sclerite.

Description. Male. Head subtriangular, interocular space approximately $1 / 3$ distance between antennae. Frons slightly elevated. Ocelli developed and deflected. Frontal suture with a cuticular invagination (Fig. 14C). Pronotum pentagonal, fore margin rounded, with rounded lateral angles, hind margin slightly curved in the medial portion (Fig. 14B). Legs short and robust. Fore-femora ventroanterior margins with two intercalated rows of spines, one with 6 or 5, and another with 33 or 32 spines of the same size; ventro-posterior margins with one large and a thin spine out of the row, 6 small spines. Middle legs ventro-anterior margins with 11 or 10 spines. Tegmina with orange lateral margins in the first half of its length (Fig. 14A). Supra-anal plate quadrangular with setae on the surface, hind margin straight and slightly rounded laterally, bilobed with a slight invagination in the median portion. Subgenital plate asymmetrical with long styles, left funneled in the apical region, right with same caliper all along. L1 sclerite with apical region with two distinct parts: a lateral branch curved, rounded and smooth with some small spines, and a curved region with grooves in its interior and a projection with a rounded end directed upwards at its right side (Fig. 14G, H). L2d sclerite hook with long apical region and rounded curvature of the margin near the notch (Fig. 14F, I). R2 sclerite cleft curved inward with a wide and very sclerotized apex directed forward (Fig. 14D). Sclerite N tiny in dorsal and large and wide in ventral view. R3d with a clear prominence like a tooth in ventral view (Fig. 14D, E). R3v sclerite with quadrangular and truncated latero-distal region, and caudal branch near the tooth from R3d sclerite (Fig. 14E).

Female (Paratype). Head rounded, with wide interocular space measuring approximately $1 / 2$ the distance between the antennal sockets. Eyes with straight interocular margin. Ocelli developed and slightly deflected. Frontal suture with a cuticular invagination. Clypeus distal half transparent yellow and larger (Fig. 15D). Pronotum subtriangular with anterior region rounded and slightly concave near 
the margins; dorsal region rough with deep striae, lateral angles rounded ending in a corner and hind margin slightly curved in the median region (Fig. 15B). Tegmina with little rounded lateral anterior angles, orange lateral margins, and rounded and curved hind margins. Long, reaching the fifth abdominal tergite (Fig. 15A). Legs short and robust. Fore-femora ventro-anterior margins with 31 or 32 spines of the same size; ventro-posterior margins with 3 spines. Middle legs ventro-anterior margins with 5 spines. Supra-anal plate bilobed with a very small median incision. Lobe lateral margins slightly rounded and posterior margin straight (Fig. 15C). Tergites with rounded lateral angles (Fig. 15A).

Measurements (mm). Holotype m\#: Body length 52.80; pronotum length $12.05 \times 17.35$ maximum width; tegmen length $40.75 \times 14.70$ width; interocular width 1.7 ; interantennal width between sockets 5.5. Paratypes m\#: Body length $52.60-64.30$; pronotum length $11.15-14.13 \times 15.08-19.07$ maximum width; tegmen length $36.16-42.34 \times 13.81-20.73$ width; interocular width $0.9-1.2$; interantennal width between sockets $2.5-3.1$.

Allotype f\#: Body length 42.52; pronotum length $11.03 \times 17.86$ maximum width; tegmen length 17.05 $\times 12.55$ width; interocular width 3.1; interantennal width between sockets 5.6. Paratypes f\#: Body length $39.15-47.18$; pronotum length $10.04-12.22 \times 16.12-19.41$ maximum width; tegmen length $14.86-18.72 \times 09.92-13.34$ width; interocular width $1.4-1.6$; interantennal width between sockets $2.7-3.0$.

Coloration. Holotype m\#: General coloration dark brown (Fig. 14A). Pronotum dark brown with the anterior margin yellowish brown; central disk orange brown with scattered dark brown marks (Fig. 14 B). Head dark brown; clypeus and labrum yellowish brown. Antennae with basal segments dark pigmented and apical segments whitish yellow. Ocelli pale brown (Fig. 14C). Legs dark brown and spines brown; pulvilli white, tarsal claws and arolia light brown. Tegmina with orange lateral margins and abdomen following general coloration of body (Fig. 14A).

Etymology. The word kaingangue derives from the Tupi - Guarani. It is the name of an Indian group originally distributed from São Paulo to Rio Grande do Sul. The name is an allusion to the similarity of their distribution ranges and a tribute to this people that were certainly aware of the existence of this cockroach.

Distribution. Brazil (São Paulo, Santa Catarina, Rio Grande do Sul). See Fig. 17 for details.

\section{Monastria sagittata Tarli, Grandcolas \& Pellens sp. n.}

Figure 16. 
778 Type material. Holotype m\#. Brazil, Minas Gerais, Serra do Cipó. March 1967, coll. D. Vital 779 (MZUSP).

781 Diagnosis. This species is characterized by having pronotum with shallow, smooth and slightly striated dorsal surface; wide lateral margins with sharp angles. Tegmina anal field wide with the CuP vein perpendicular to the lateral. Subgenital plate asymmetrical with one small style. L1 sclerite with a distinct spear shaped apical region, hind margin with a large non-sclerotized projection, and fore region with a small projection directed upwards. Lateral branch small with strong teeth and spines. L2d sclerite, hook with subconical and narrow anterior region, very short and curved and internal ventral margin strongly convex.

Description. Male. Head subtriangular, with interocular space measuring approximately $1 / 3$ of the distance between the antennal sockets. Ocelli developed and slightly deflected; frontal suture with a cuticular invagination (Fig. 16C). Pronotum broad, transverse and pentagonal; dorsal surface shallow, smooth and slightly striated; anterior margin rounded; lateral margins wider with sharp angles; hind margin nearly straight (Fig. 16B). Tegmina characterized by a wide anal field with the CuP vein perpendicular to the lateral (Fig. 16A). Legs short and robust. Fore-femora ventro-anterior margins with 21 or 20 spines of the same size; ventro-posterior margins with 4 spines. Middle-legs ventroanterior margins with 5 or 4 large spines. Supra-anal plate quadrangular with setae on the surface, hind margin straight and slightly rounded laterally, bilobed with narrower lobes and strong invagination in the median portion. Subgenital plate asymmetrical with one small style. L1 sclerite with a roughly triangular spear-shaped apical region, hind margin with a large non-sclerotized projection, fore region with a small lateral projection directed upwards, and lateral branch small with strong teeth and spines (Fig. 16G, H). L2d sclerite hook with subconical and narrow anterior region, very short, curved and internal ventral margin strongly convex (Fig. 16F, I). R2 sclerite cleft slightly curved inwards with the apex slightly sclerotized (Fig. 16D, E). The other sclerites were partially destroyed with an unhappy manipulation.

805

806

Female. Unknown

Measurements (mm). Holotype m\#: Body length 51.28; pronotum length $11.94 \times 21.54$ maximum width; tegmen length $41.97 \times 17.00$ width; interocular width 1.8 ; interantennal width between sockets 5.4 . 
813 Coloration. Holotype m\#: General coloration pale brown (Fig. 16A). Pronotum pale brown with a

814 buff anterior margin; central disk brown ochre with scattered dark brown marks (Fig. 16B). Head with

815 dark brown interocular space, orange frons and amber clypeus and labrum. Antennae with segments

816 yellowish brown. Ocelli brown (Fig. 16C). Legs and spines yellowish brown; pulvilli yellow whitish,

817 tarsal claws and arolia yellowish brown. Tegmina and abdomen following general coloration of body

818 (Fig. 16A).

819

820 Etymology. The name "sagittata" derives from the Latin sagitta, meaning arrow, referring to arrow-

821 shaped apex of the L1 sclerite.

822

823 Distribution. Brazil (Minas Gerais). See Fig. 17 for details.

824

825 Hiereoblatta papillosa (Thunberg, 1826) comb. $\mathbf{n}$.

826 Figure 18.

827

828 Blatta papillosa Thunberg, 1826: 276; Scudder, 1868: 18.

829 Monastria papillosa Shelford, 1907 -1908: 467; Kirby, 1910: 565; Princis, 1949: 66; Princis, 1963 :

830142.

831

832 Among all the material examined to revise the genus Monastria was the type of Blatta papillosa

833 Thunberg, 1826. This species was assigned to Monastria very early and maintained until today after

834 being synonymized several times. As can be seen in the Fig. 18, the coloration, pronotum, head,

835 tegmina and general shape of this specimen does not correspond to those that characterize the genus

836 Monastria. In fact, the general characteristics of this species are in accordance with the genus

837 Hiereoblatta Rehn, 1937 (see Fig. 1D) as described in our identification key. Here, for the sake of

838 delimiting the genus Monastria we propose the new combination Hiereoblatta papillosa. We do not

839 propose here to solve the synonyms of this species because, as was the case for Monastria, the genus

840 Hiereoblatta needs to be revised, and any proposition of solution of the several synonymies would be

841 premature without a careful study.

842

\section{Conclusions}

844

845 With this revision, the genus Monastria is now known as having 8 species, and one of the species

846 previously accepted as belonging to this genus is now assigned to Hiereoblatta. The records of

847 occurrence of the specimens analyzed here indicate that the distribution range of the genus is much

848 broader than previously known, and confirm the initial hypothesis of an endemism to the Neotropical

849 Atlantic forest. The characterization of juveniles and adults of the radiation of Blaberinae of the 
850 Atlantic forest and the determination keys provided will significantly contribute to a rapid

851 identification of the species belonging to this group that are often found together in the field.

852

853 Acknowledgements

854

855 Many people facilitated our work along several sessions in the field. We thank ICMBio for authorizing 856 the fieldwork (License No. 44118 - 1), and the people directly working on the conservation units we 857 visited; Jose Wellington de Morais (Instituto Nacional de Pesquisas da Amazônia) for support with 858 fieldwork license; the people working for the environment and agricultural secretaries from Joinville, 859 Campo Alegre and Florianópolis, for assuring our access to reserves from these municipalities; and 860 people that gave us access to private reserves under their responsibilities: the owner of Hotel Dona 861 Francisca in Joinville (SC), Sr. Gilson and Sr. Egon in Campo Alegre (SC), Kevin Flesher from the 862 reserve of Society Michelin at Ituberá (BA), and John Keller and Igu in Foz de Iguaçu (PR). We are 863 also very greatful to Luciana Ribeiro, from Instituto Latino-Americano de Economia, Sociedade e

864 Política, Patricia Garcia Carvalho, Joaquim Buchaim from Faculdades Anglo, for facilitating our study 865 in Foz do Iguaçu, Aurora do Iguaçu, and at Estação Ecológica Ari Cavalca. Finally, we thank the 866 curators of several collections who loaned the material to this study: Eliana Marques Cancello (Museu 867 de Zoologia - University of São Paulo), José Albertino Rafael (Instituto Nacional de Pesquisas da 868 Amazônia), Sônia Maria Lopes Fraga (Museu Nacional do Rio de Janeiro), George Beccaloni (Natural 869 History Museum of London), Peter J. Schwendinger (Muséum d'histoire naturelle de la Ville de 870 Genève). We would also like to thank Hans Mejlon (Uppsala University) for providing the pictures of 871 the types from Thunberg. We thank Simon Poulain (MNHN) for the support with the digital images.

872 VDT also thanks CAPES Foundation - Ministry of Education, Brazil for the scholarship (Grant

873 Number - 6062/13-0). We thank the ATM "Biodiversité actuelle et fossile. Crises, stress,

874 restaurations et panchronisme : le message systématique" and ATM "Savoirs Naturalistes, expertise et 875 politiques de la biodiversité" (MNHNP) for financial support for field work.

\section{References}

878

879 Brunner von Wattenwyl, C. (1865) Nouveau Système des Blattaires. Vienne : G. Braumüller, 426 pp.

880 Burmeister, H. (1838) Blattina. In: Enslin, T.Ch.F. (Ed), Handbuch der Entomologie, Volume 2,

881 Berlin, pp. 469-517.

882 Brugerolle, G., Silva-Neto, I.D., Pellens, R. \& Grandcolas, P. (2003) Electron microscopic

883 identification of the intestinal protozoan flagellates of the xylophagous cockroach Parasphaeria

884 boleiriana from Brazil. Parasitology Research 90, 249-256.

885 https://doi.org/10.1007/s00436-003-0832-7

886 Dalman, J.W. (1823) Analecta entomologica. Typis Lindhianis, Holmiae, 104 pp. 
Eschscholtz, J.F. (1822) Entomographien. Erste Lieferung. Berlin, G. Reimer, $128+3$ pp, 2 col. pls. Finot, A. (1897) Catalogue des Orthoptères de l'Amérique Méridionale décrits jusqu'à ce jour, 1896. Actes de la Société Scientifique du Chili, 7, 169-220.

Grandcolas, P. (1991) Descriptions de nouvelles Zetoborinae Guyanaises avec quelques remarques sur la sous-famille. Bulletin de la Société Entomologique de France, 95, 241-246.

Grandcolas, P. (1993a) L'écologie de la répartition de Thanatophyllum akinetum en Guyane française (Insecta, Blattaria). Biogeographica 69, 73-86.

Grandcolas, P. (1993b) Monophylie et structure phylogénétique des [Blaberinae + Zetoborinae + Gyninae + Diplopterinae] (Dictyoptera : Blaberidae). Annales de la Société entomologique de France (N.S.), 29, 195-222.

Grandcolas, P. (1993c). The origin of biological diversity in a tropical cockroach lineage: a phylogenetic analysis of habitat choice and biome occupancy. Acta Oecologica, 14, 259-270.

Grandcolas, P. (1996) The phylogeny of cockroach families: a cladistic appraisal of morphoanatomical data. Canadian Journal of Zoology, 74, 508-527. https://doi.org/10.1139/z96-059

Grandcolas, P. (1998). The evolutionary interplay of social behavior, resource use and anti-predator behavior in Zetoborinae + Blaberinae + Gyninae + Diplopterinae cockroaches: a phylogenetic analysis. Cladistics, 14, 117-127. https://doi.org/10.1006/clad.1998.0062

Grandcolas, P. \& Pellens, R. (2002) A new species of the cockroach genus Parasphaeria (Dictyoptera: Blattaria: Blaberidae) from the Atlantic forest in Brazil. Transactions of the American Entomological Society 128, 23-29.

Grandcolas, P. \& Pellens, R. (2012) Capitulo 27. Blattaria. In: Rafael, J.A., Rodrigues de Melo, G.A., Barros de Carvalho, C.J., Casari, S.A. \& Constantino, C.J. (Eds.), Insetos do Brasil. Diversidade e Taxonomia. Ribeirao Preto, Holos Editora, pp. 333-346.

Hebard, M. (1921) South American Blattidae from the Museum National d'Histoire Naturelle, Paris, France. Proceedings of the Academy of Natural Sciences of Philadelphia, 73, 193-304.

\section{Kirby, W.F. (1904) A Synonymic Catalogue of Orthoptera. Orthoptera Euplexoptera, Cursoria et} Goessinia (Forficulidae, Hemimeridae, Blattidae, Mantidae, Phasmidae). Vol. I. Taylor \& Francis, London, $501 \mathrm{pp}$.

Kirby, W.F. (1910) A Synonymic Catalogue of Orthoptera (Orthoptera Saltatoria, Locustidae vel Acridiidae) Vol. III Taylor and Francis, London, 674pp.

Legendre, F., Nel, A., Svenson, G.J., Robillard, T., Pellens, R. \& Grandcolas, P. (2015) Phylogeny of Dictyoptera: Dating the Origin of Cockroaches, Praying Mantises and Termites with Molecular Data and Controlled Fossil Evidence. PLoS ONE, 10 (7), e0130127

$$
\text { https://doi.org/10.1371/journal.pone.0130127 }
$$


Linnaeus, C. (1758) Systema naturae per regna tria naturae, secundum classes, ordines, genera, species, cum characteribus, differentiis, synonymis, locis. Tomus I. Editio decima, reformata. - pp. [1-4], 1-824. Holmiæ.

McKittrick, F.A. (1964) Evolutionary studies of cockroaches. Cornell University Agriculture Experimental Station, 389, 1-197.

Pellens, R. \& Grandcolas, P. (2003) Living in Atlantic forest fragments: life habits, behaviour and colony structure of the cockroach Monastria biguttata (Dictyoptera, Blaberidae, Blaberinae) in Espirito Santo, Brazil. Canadian Journal of Zoology, 82, 1929-1937.

$$
\text { https://doi.org/10.1139/z03-191 }
$$

Pellens, R. \& Grandcolas, P. (2007) The conservation refugium value of small and disturbed Brazilian Atlantic forest fragments for the endemic ovoviviparous cockroach Monastria biguttata (Insecta: Dictyoptera, Blaberidae, Blaberinae). Zoological Science, 24, 11-19. https://doi.org/10.2108/zsj.24.11

Pellens, R. \& Grandcolas P. (2008) Catalogue of Blattaria (Insecta) from Brazil. Zootaxa 1709, 1-109. Pellens, R., Grandcolas, P. \& Silva-Neto, I.D. da (2002) A new and independently evolved case of xylophagy and the presence of intestinal flagellates in the cockroach Parasphaeria boleiriana (Dictyoptera, Blaberidae, Zetoborinae) from the remnants of the Brazilian Atlantic forest. Canadian Journal of Zoology 80, 350-359.

$$
\text { https://doi.org/10.1139/z01-230 }
$$

Pellens, R., D'Haese, C., Bellés, X., Piulachs, M. D., Legendre, F., Wheeler, W., Grandcolas, P. (2007a). The evolutionary transition from subsocial to eusocial behavior: phylogenetic and ecological evidence for modification of the "shift-in-dependent-care" hypothesis with a new prototermite model. Molecular Phylogenetics and Evolution 43, 616-626.

$$
\text { doi:10.1016/j.ympev.2006.12.017 }
$$

Pellens, R., Legendre, F., Grandcolas, P. (2007b). Phylogenetic analysis of social behavior evolution in [Zetoborinae + Blaberinae + Gyninae + Diplopterinae] cockroaches: an update with the study of endemic radiations from the Atlantic forest. Studies in Neotropical Fauna and Environment, 42, 25-31. https://doi.org/10.1080/01650520600879538

Princis, K. (1946) Colombianische Blattodeen, gesammelt von Herrn G. Dahl und Frau M. AlthinDahl in den Jahren 1936-1939. Kungliga Fysiografiska Sällskapet I Lund Förhandlingar, 16, 162 pp.

Princis, K. (1949) The Blattaria described by Carl Peter Thunberg. Opuscula Entomologica, 14, 6167.

Princis, K. (1951) Neue und wenig bekannte Blattarien aus dem Zoologischen Museum, Kopenhagen. Spolia Zoologica Musei Hauniensis, 12, 1-72.

Princis, K. (1958) Revision der Walkerschen un Kirbyschen Blattarientypen im British Museum of Natural History, London. II. Opuscula Entomologica, 23, 59-75. 
960

961

962

963

964

965

966

967

968

969

970

971

972

973

974

975

976

977

978

979

980

981

982

983

984

985

986

987

988

989

990

991

992

993

994

995

Princis, K. (1963) Blattariae: Suborde Polyphagoidea: Fam.: Homoeogamiidae, Euthyrrhaphidae, Latindiidae, Anacompsidae, Atticolidae, Attaphilidae; Subordo Blaberoidea: Fam. Blaberidae. In: Beier M. (Ed.) Orthopterorum Catalogus, Pars 4. Uitgeverij Dr. W. Junk's - Gravenhage, pp. 77172.

Rehn, J.A.G. (1911) Notes on Paraguayan Orthoptera, with descriptions of a new genus and four new species. Entomological News, 22, 247-258.

Rehn, J.A.G. (1913) A contribution to the knowledge of the Orthoptera of Argentina. Proceedings of the Academy of Natural Sciences of Philadelphia, 65, 273-379.

Rehn, J.A.G. (1915) A further contribution to the knowledge of the Orthoptera of Argentina.

$$
\text { Proceedings of the Academy of Natural Sciences of Philadelphia, 67, 270-292. }
$$

Rehn, J.A.G. (1920) Records and descriptions of Brazilian Orthoptera. Proceedings of the Academy of Natural Sciences of Philadelphia, 72, 214-293.

Rehn, J.A.G. (1937) New or little known Neotropical Blattidae (Orthoptera). Number four.

Transactions of the American Entomological Society, 63, 207-258.

Rehn, J.A.G. (1940) A new genus of Blattidae (Orthoptera) from Brazil. Notulae Naturae of Academy of Natural Sciences of Philadelphia, 58, 1-6.

Roth, L.M. (1970a) Evolution and taxonomic significance of reproduction in Blattaria. Annual Review of Entomology, 15, 75-96.

Roth, L. M. 1970b. The Male Genitalia of Blattaria. IV. Blaberidae: Blaberinae. Psyche, 308-342.

Roth, L.M. (2003) Systematics and phylogeny of cockroaches (Dictyoptera: Blattaria). Oriental Insects, 37, 1-186 http://dx.doi.org/10.1080/00305316.2003.10417344

Saussure, H. (1864a) Orthoptères de L'Amérique Moyenne. Mémoires pour servir à l'histoire naturelle du Mexique, Genève, 255 pp.

Saussure, H. (1864b) Blattarum novarum species aliquot. Revue et Magasin de Zoologie, 2, 341-349.

Saussure, H. (1870) Famille des Blattides. In: Recherches zoologique pour servir a l'histoire de la faune de l'Amérique Centrale et du Mexique. Imprimerie Impériale, Paris. Vol. 4, pp. 120. Scudder, S.H. (1868) Catalogue of the Orthoptera of North America described previous to 1867.

$$
\text { Smithsonian miscellaneous collections, 189, } 13 \mathrm{pp} \text {. }
$$

Serville, J.G.A. (1831) Revue méthodique des insectes de l'Ordre des Orthoptères. Annales des Sciences Naturelles, 22, 262-292.

Serville, J.G.A. (1839) Histoire Naturelle des Insectes - Orthoptères. Librairie encyclopédique de Roret, Paris, 776 pp.

Shelford, R. M. A. (1907-1908) Studies of the Blattidae. The Blattidae described by Linnaeus, De Geer and Thunberg. Transactions of the Entomological Society of London, 4, 455-470.

Stâl, C. (1855) Entomologiska Notiser. Ofversigt af Kongliga Vetenskaps-Academien Förhandlingar, $12,342-355$. 
Thunberg, C.P. (1826) Blattarum novae species descriptae. Mémoires de l'Académie impériale des sciences de St. Pétersbourg, 10, 276 pp.

Walker, F. (1868) Catalogue of the specimens of Blattariae in the collection of the British Museum. British Museum, London, 239 pp.

\section{Legends}

Figure 1. Five genera of Blaberinae endemic from the Neotropical Atlantic forest. Habitus, dorsal view: A) Monastria; B) Petasodes; C) Minablatta; D) Hiereoblatta; E) Monachoda. Scales: $1 \mathrm{~cm}$.

Figure 2. Juveniles stages of five genera of Blaberinae endemic to the Neotropical Atlantic forest. Habitus, dorsal view: A) Monastria, B) Petasodes, C) Minablatta, D) Hiereoblatta, E) Monachoda. Scales: $1 \mathrm{~cm}$.

Figure 3. Scanning electron photographs showing dorsal cuticular microsculptures of juveniles: A) Monastria, B) Petasodes, C) Minablatta, D) Hiereoblatta, E) Monachoda. Note that the scale differs among pictures.

Figure 4. Monastria biguttata, female holotype. Scales: Habitus=1 $\mathrm{cm}$

Figure 5. Monastria biguttata, ổ: A) Habitus, dorsal view; B) Pronotum, dorsal view; C) Head, ventral view; D) Right phallomere, dorsal view; E) Right phallomere, ventral view; F) Left phallomere (L2d), ventral view; G) Median sclerite (L1), dorsal view; H) Median sclerite (L1), detail; I) Left phallomere (L2d), dorsal view. Scales: Habitus $=1 \mathrm{~cm}$, Pronotum $=5 \mathrm{~mm}$, Head $=2 \mathrm{~mm}$, all others $=1 \mathrm{~mm}$.

Figure 6. Figs. A-D, Monastria biguttata, $९$ : A) Habitus, dorsal view; B) Pronotum, dorsal view; C) Supra-anal plate, dorsal view; D) Head, ventral view. Figs. E-H, Monastria similis, of: E) Habitus, dorsal view; F) Pronotum, dorsal view; G) Supra-anal plate, dorsal view; H) Head, ventral view. Scales: Habitus $=1 \mathrm{~cm}$, Pronotum $=5 \mathrm{~mm}$, Supra-anal plate $=5 \mathrm{~mm}, \mathrm{Head}=2 \mathrm{~mm}$.

Figure 7. Male juveniles of Monastria in different stages of development. Scales: Habitus $=5 \mathrm{~mm}$. Note the rough surface covered by particles in all stages.

Figure 8. Monastria similis, $\widehat{\jmath}:$ A) Habitus, dorsal view; B) Pronotum, dorsal view; C) Head, ventral view; D) Right phallomere, dorsal view; E) Right phallomere, ventral view; F) Left phallomere (L2d), 
1032

1033

1034

1035

1036

1037

1038

1039

1040

1041

1042

1043

1044

1045

1046

1047

1048

1049

1050

1051

1052

1053

1054

1055

1056

1057

1058

1059

1060

1061

1062

1063

1064

1065

1066

1067

ventral view; G) Left phallomere (L2d), dorsal view; H) Median sclerite (L1), dorsal view; I) Median sclerite (L1), detail (see Fig. 5 for abbreviations). Scales: Habitus $=1 \mathrm{~cm}$, Pronotum=5 mm, Head=2 $\mathrm{mm}$, all other figures $=1 \mathrm{~mm}$.

Figure 9. Figs. A-D, Monastria angulata, Syntype ${ }_{+}:$A) Habitus, dorsal view; B) Pronotum, dorsal view; C) Supra-anal plate, dorsal view; D) Head, ventral view. Figs. E-H, Monastria cabocla sp. n. Allotype $q$ : E) Habitus, dorsal view; F) Pronotum, dorsal view; G) Supra-anal plate, dorsal view; H) Head, ventral view. Scales: Habitus $=1 \mathrm{~cm}$, Pronotum $=5 \mathrm{~mm}$, Supra-anal plate $=5 \mathrm{~mm}$, Head $=2 \mathrm{~mm}$.

Figure 10. Monastria cabocla sp. n., Holotype ${ }^{\circledR}:$ A) Habitus, dorsal view; B) Pronotum, dorsal view; C) Head, ventral view; D) Right phallomere, dorsal view; E) Right phallomere, ventral view; F) Left phallomere (L2d), ventral view; G) Median sclerite (L1), dorsal view; H) Median sclerite (L1), detail; I) Left phallomere (L2d), dorsal view (see Fig. 5 for abbreviations). Scales: Habitus $=1 \mathrm{~cm}$, Pronotum $=5 \mathrm{~mm}$, Head $=2 \mathrm{~mm}$, all others $=1 \mathrm{~mm}$.


C) Head, ventral view; D) Right phallomere, dorsal view; E) Right phallomere, ventral view; F) Left phallomere (L2d), ventral view; G) Left phallomere (L2d), dorsal view; H) Median sclerite (L1), dorsal view; I) Median sclerite (L1), detail (see Fig. 5 for abbreviations). Scales: Habitus=1 cm, Pronotum $=5 \mathrm{~mm}$, Head $=2 \mathrm{~mm}$, all others $=1 \mathrm{~mm}$.

Figure 12. Figs. A-D, Monastria itubera sp. n., Allotype $\odot$ : A) Habitus, dorsal view; B) Pronotum, dorsal view; C) Supra-anal plate, dorsal view; D) Head, ventral view. Figs. E-H, Monastria itabuna sp. n., Allotype $\odot$ : E) Habitus, dorsal view; F) Pronotum, dorsal view; G) Supra-anal plate, dorsal view; H) Head, ventral view. Scales: Habitus $=1 \mathrm{~cm}$, Pronotum $=5 \mathrm{~mm}$, Supra-anal plate $=5 \mathrm{~mm}$, Head $=2$ $\mathrm{mm}$.

Figure 13. Monastria itabuna sp. n., Holotype ổ: A) Habitus, dorsal view; B) Pronotum, dorsal view; C) Head, ventral view; D) Right phallomere, dorsal view; E) Right phallomere, ventral view; F) Left phallomere (L2d), ventral view; G) Median sclerite (L1), dorsal view; H) Median sclerite (L1), detail; I) Left phallomere (L2d), dorsal view (see Fig. 5 for abbreviations). Scales: Habitus $=1 \mathrm{~cm}$, Pronotum $=5 \mathrm{~mm}$, Head $=2 \mathrm{~mm}$, all others $=1 \mathrm{~mm}$.

Figure 14. Monastria kaingangue sp. n., Holotype $\delta^{\text {: }}$ A) Habitus, dorsal view; B) Pronotum, dorsal view; C) Head, ventral view; D) Right phallomere, dorsal view; E) Right phallomere, ventral view; F) Left phallomere (L2d), ventral view; G) Median sclerite (L1), dorsal view; H) Median sclerite (L1), 
1068 detail; I) Left phallomere (L2d), dorsal view (see Fig. 5 for abbreviations). Scales: Habitus=1cm,

1069 Pronotum $=5 \mathrm{~mm}$, Head $=2 \mathrm{~mm}$, all others $=1 \mathrm{~mm}$.

1070

1071 Figure 15. Monastria kaingangue sp. n., Allotype $\odot$ : A) Habitus, dorsal view; B) Pronotum, dorsal

1072 view; C) Supra-anal plate, dorsal view; D) Head, ventral view. Scales: Habitus=1cm, Pronotum=5mm,

1073 Supra-anal plate $=5 \mathrm{~mm}$, Head $=2 \mathrm{~mm}$.

1074

1075 Figure 16. Monastria sagittata sp. n., Holotype $\delta^{\text {A }}$ : A) Habitus, dorsal view; B) Pronotum, dorsal view;

1076 C) Head, ventral view; D) Right phallomere, dorsal view; E) Right phallomere, ventral view; F) Left

1077 phallomere (L2d), ventral view; G) Median sclerite (L1), dorsal view; H) Median sclerite (L1), detail;

1078 I) Left phallomere (L2d), dorsal view (see Fig. 5 for abbreviations). Scales: Habitus=1cm,

1079 Pronotum $=5 \mathrm{~mm}$, Head $=2 \mathrm{~mm}$, all other figures $=1 \mathrm{~mm}$.

1080

1081 Figure 17. Geographic location of sites where the different species of Monastria were collected.

1082 Monastria angulata is not in included in the map for it is only known from a specimen from Bahia,

1083 without any mention of locality.

1084

1085 Figure 18. Hiereoblatta papillosa (Thunberg, 1826) comb. n., female holotype. Not to scale. 


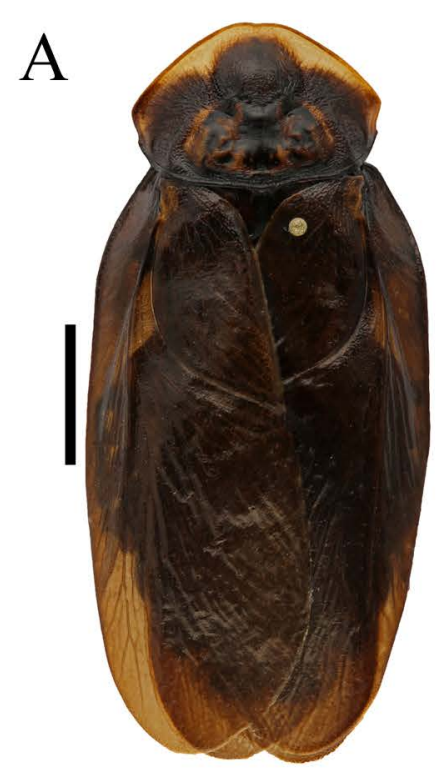

B

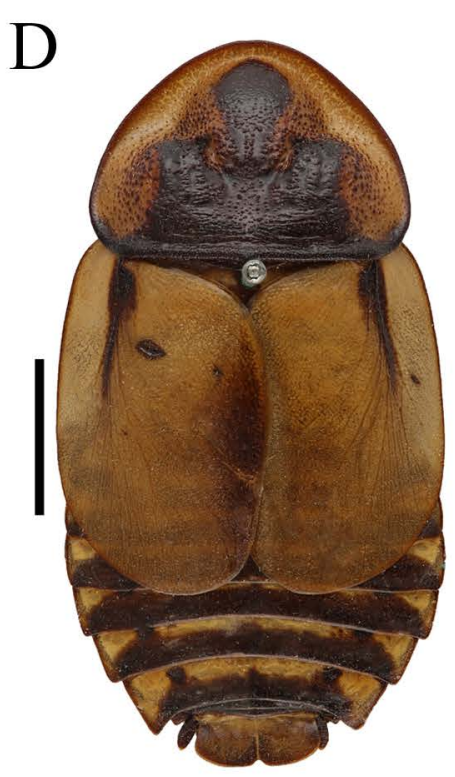

C

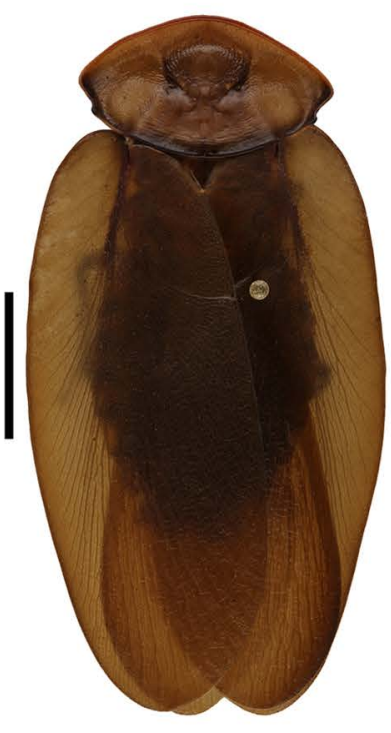

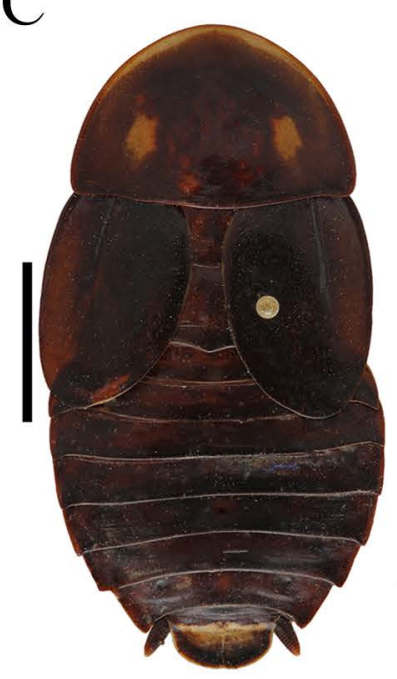

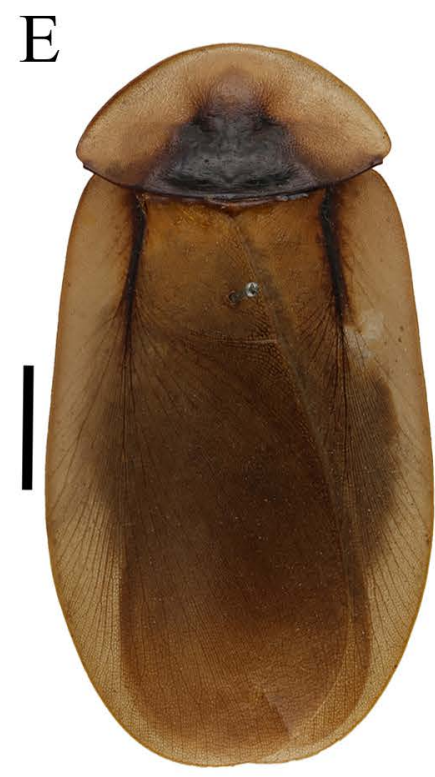

Figure 1 

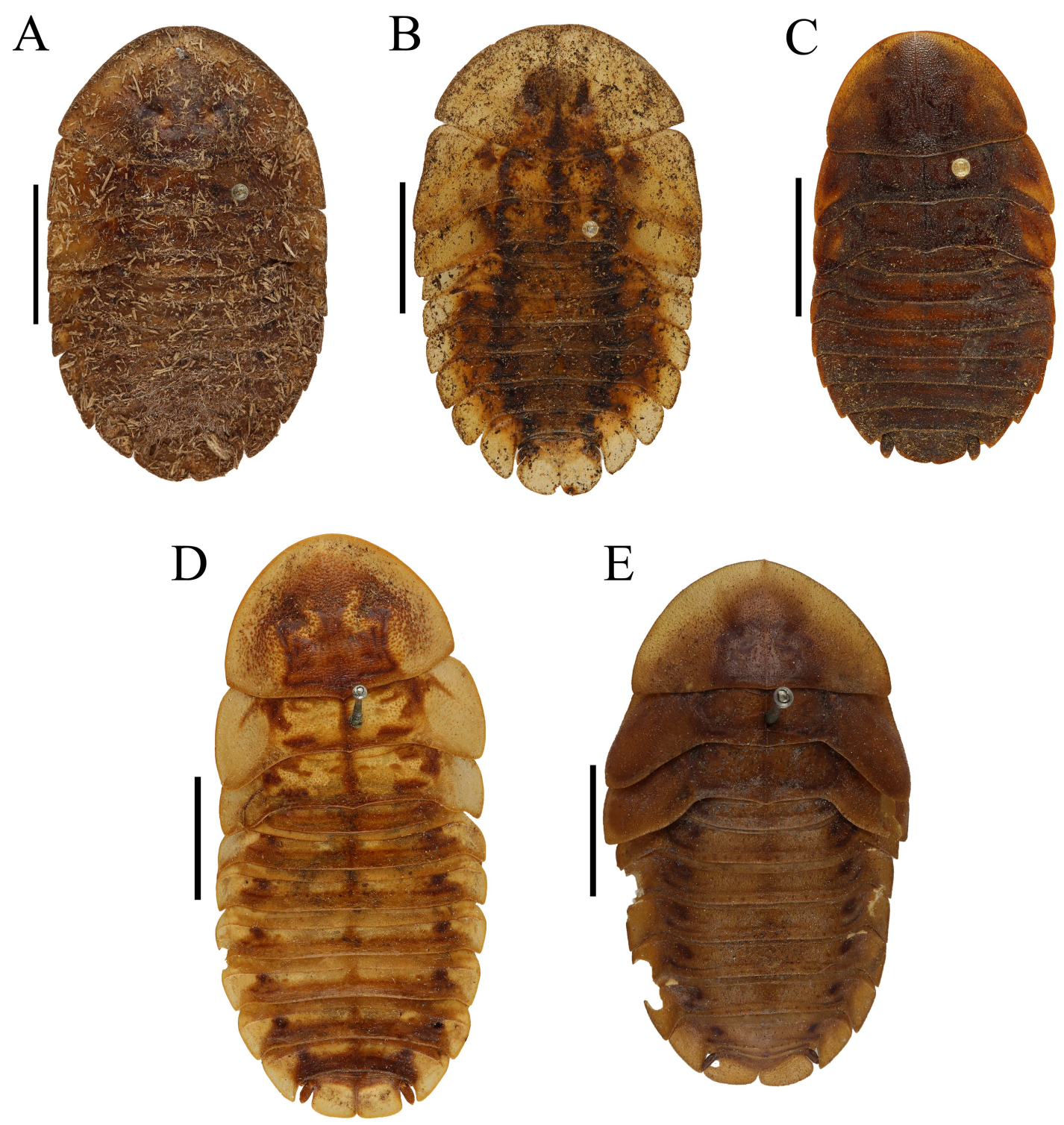

Figure 2 


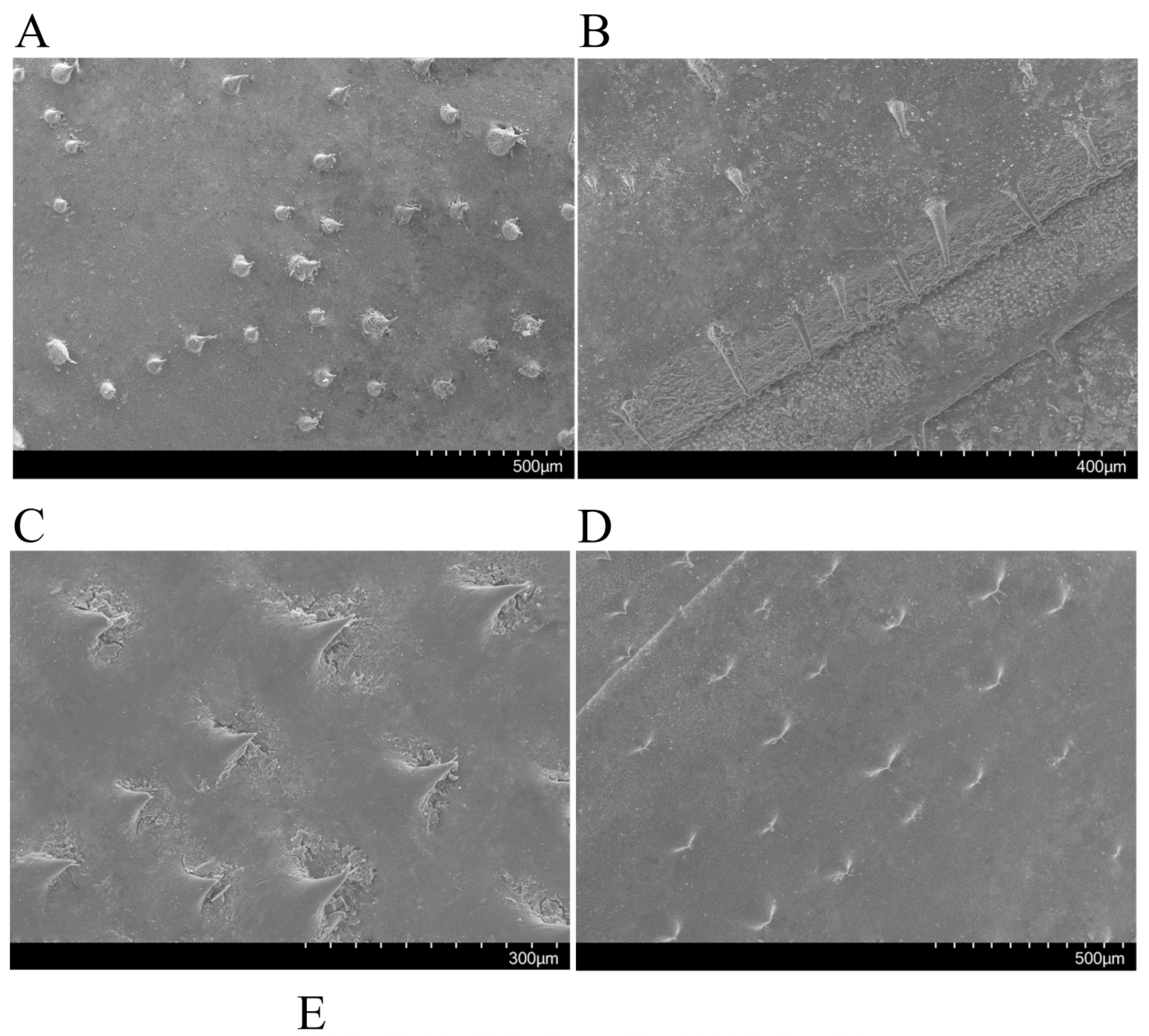





Uppsala Univ. Zool. Mus. Thunbergsami. ar. 22492 Elense bigullete Amer.merid. TYP

\section{6}

Figure 4 
A

B

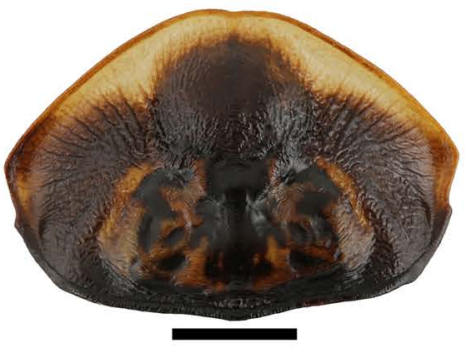

C

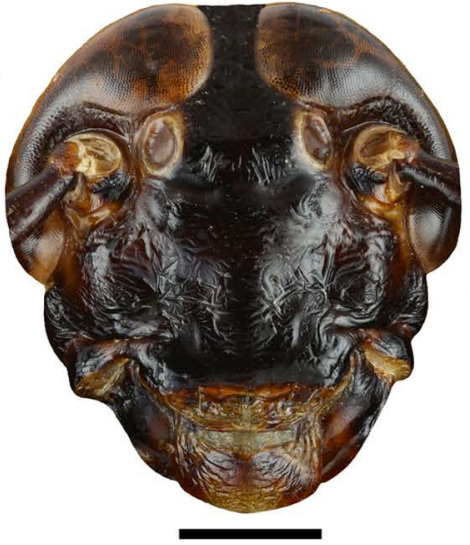

F


I

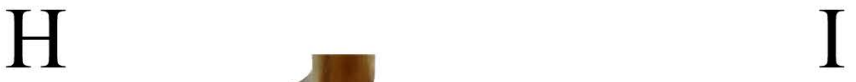

L1

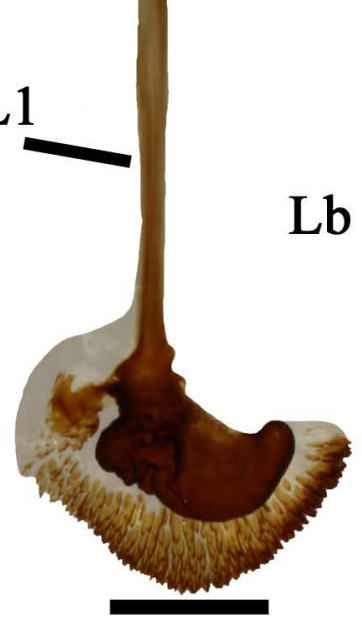

Cs

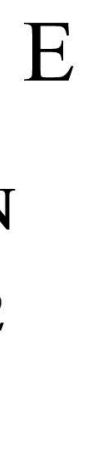

G
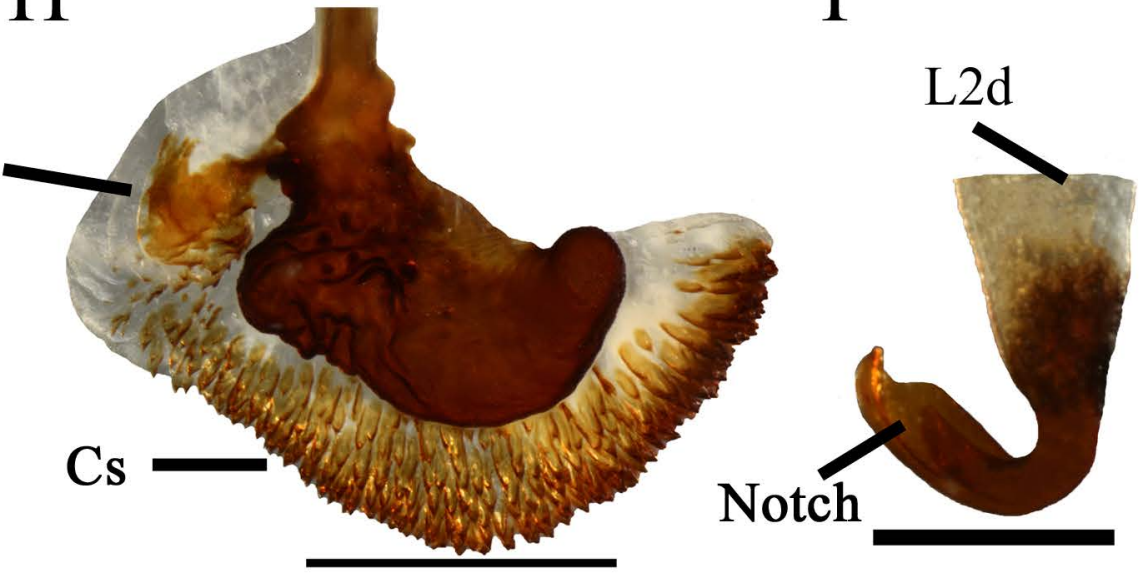

Figure 5 



E

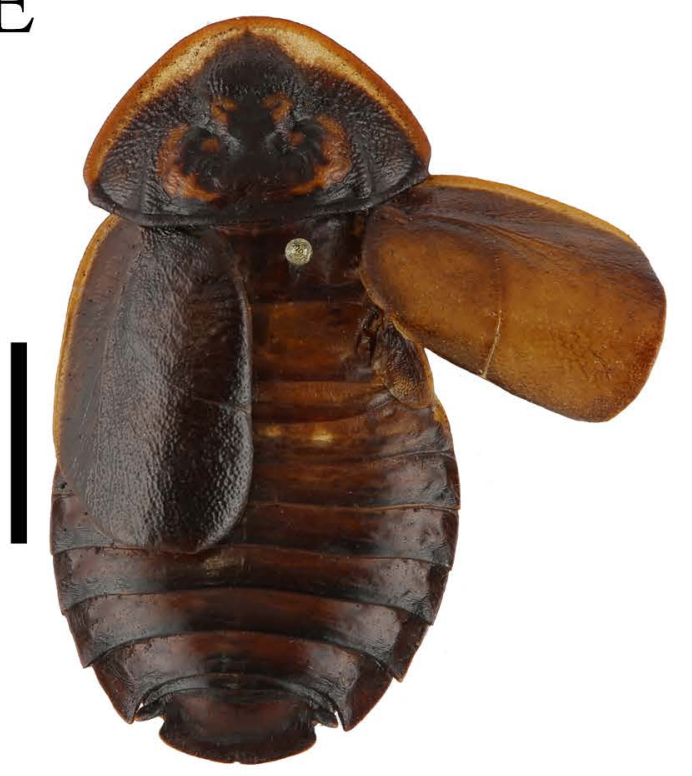

G
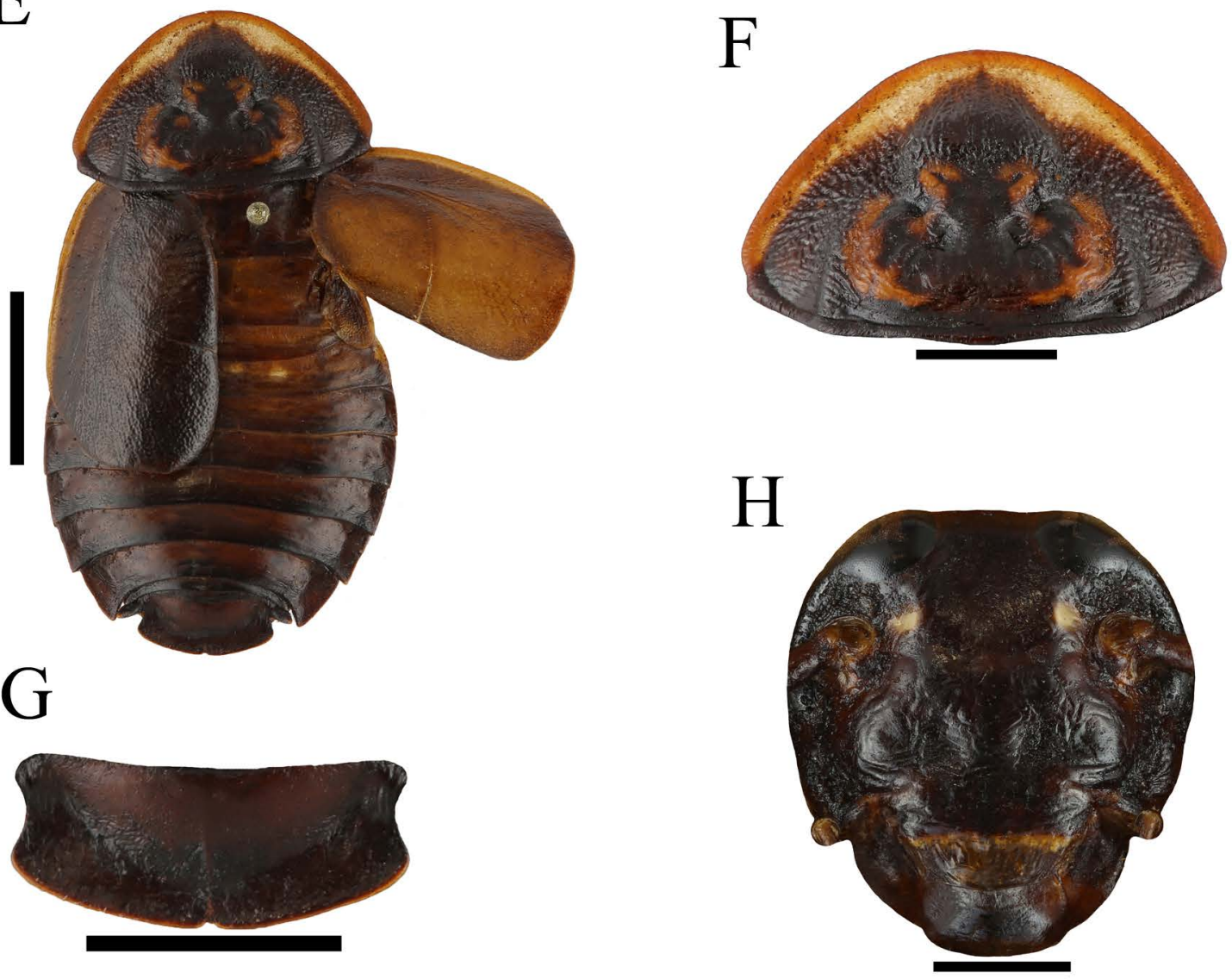

Figure 6 


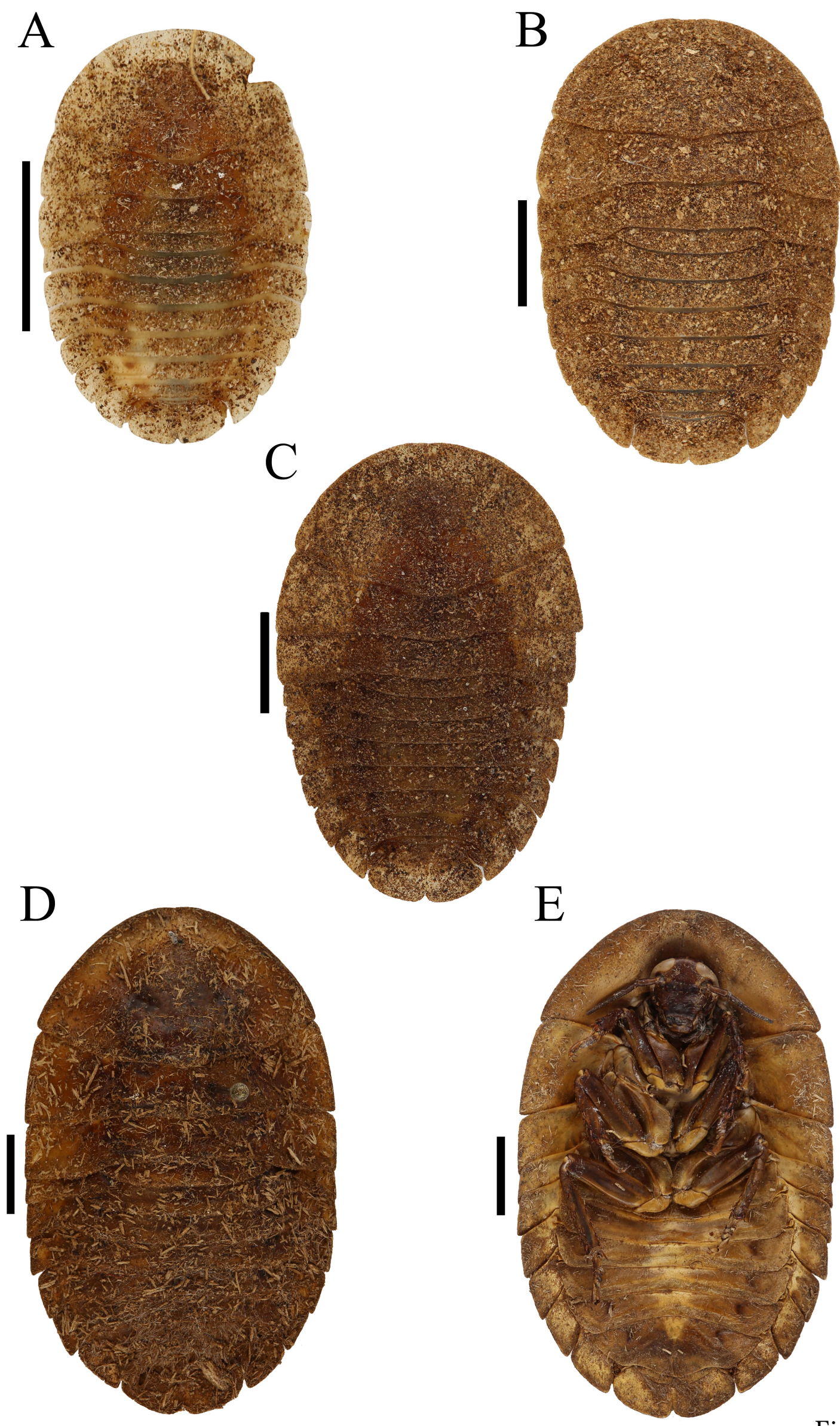

Figure 7 



D



E

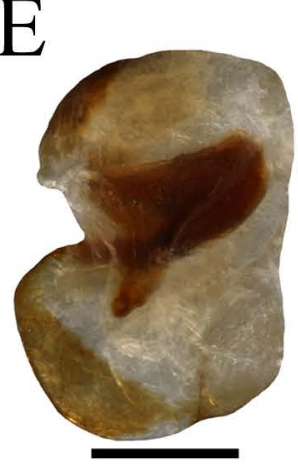

$\mathrm{H}$



F
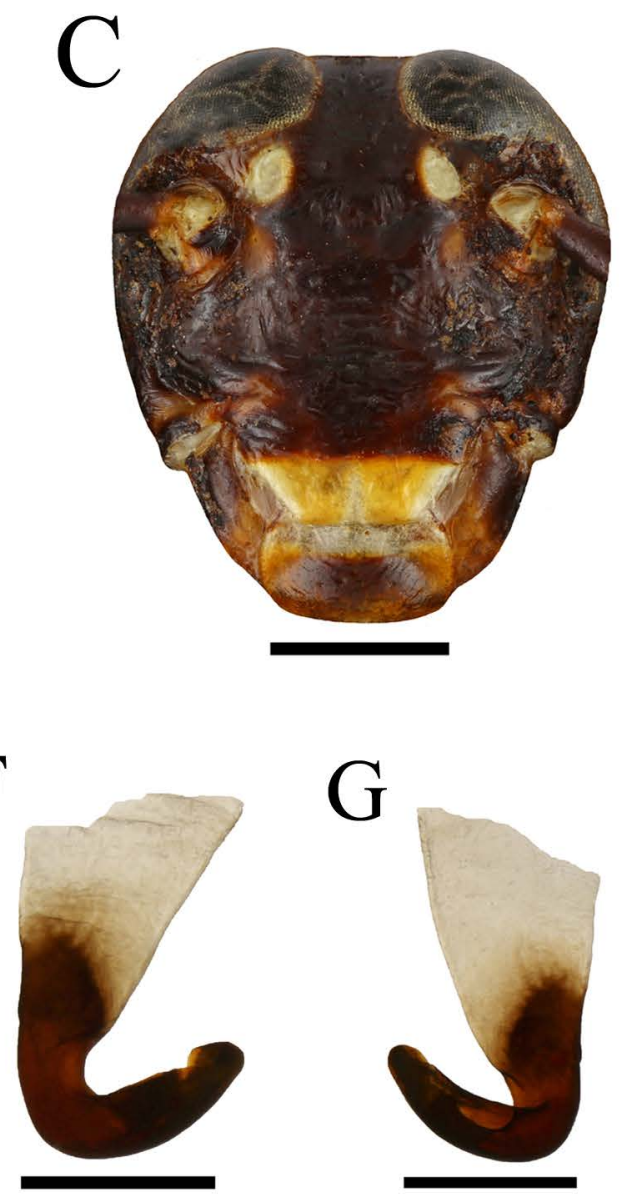

G

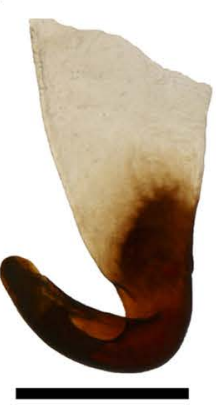

I


(e)

Nyly

Figure 8 



Figure 9 

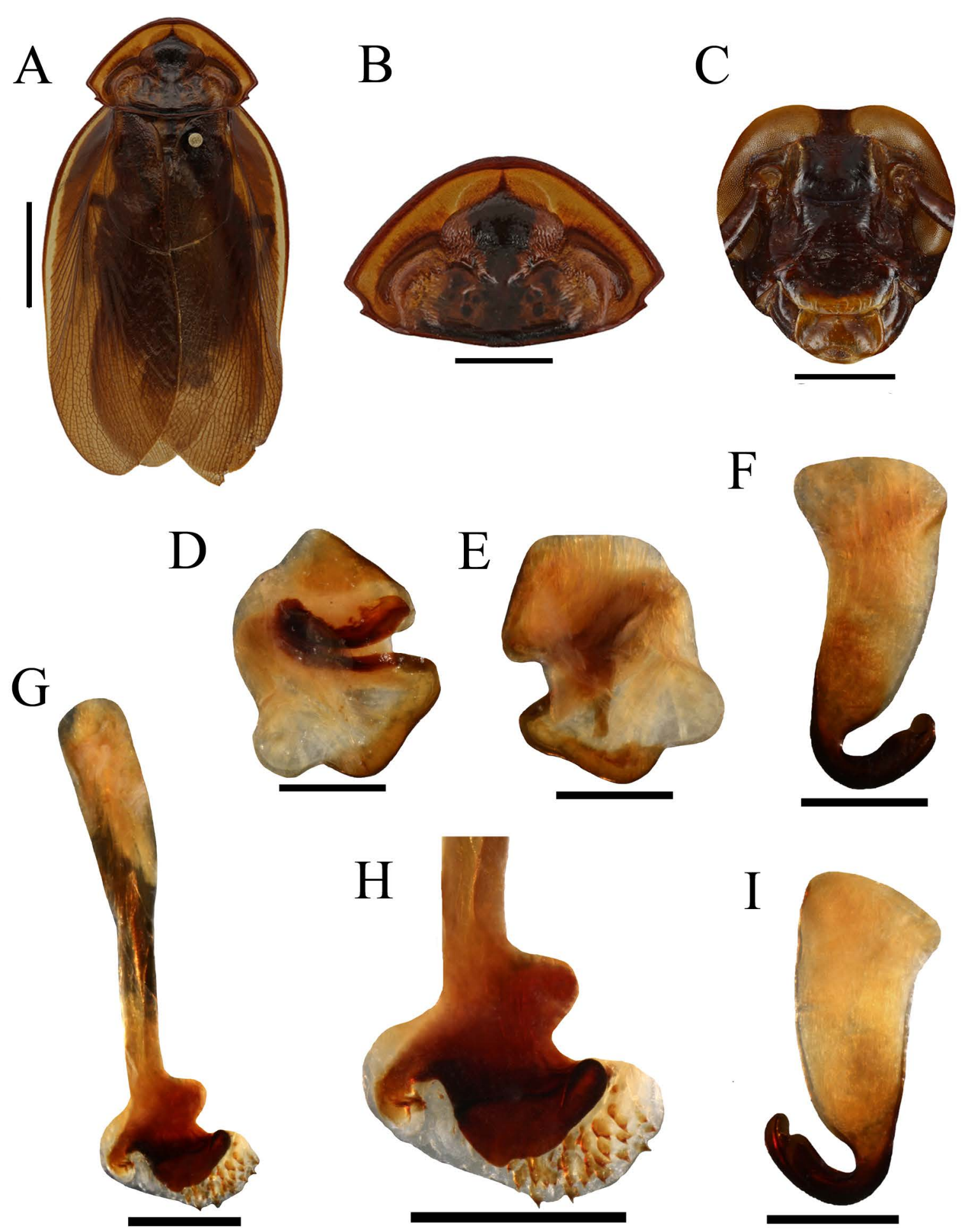

Figure 10 

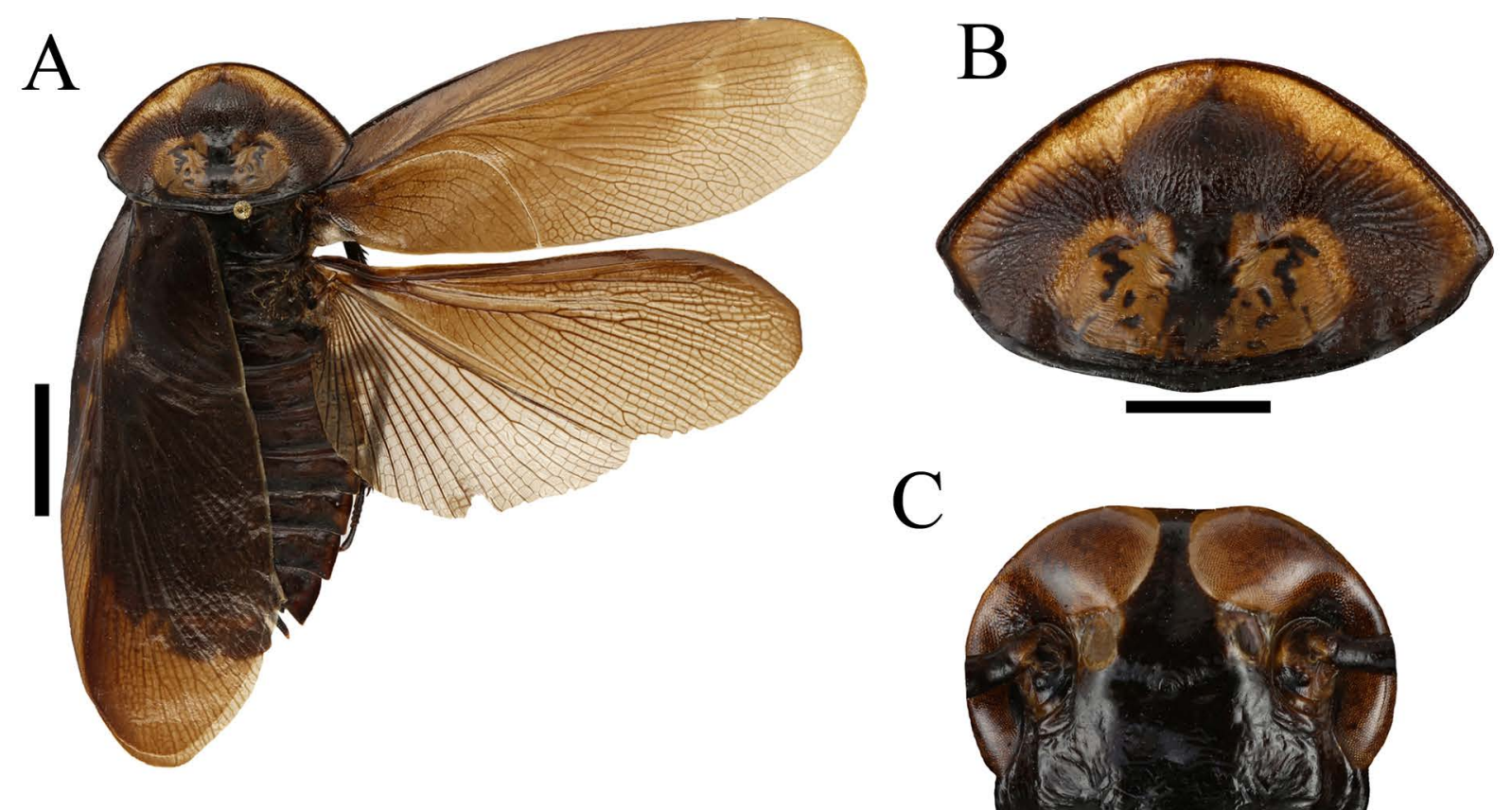

D
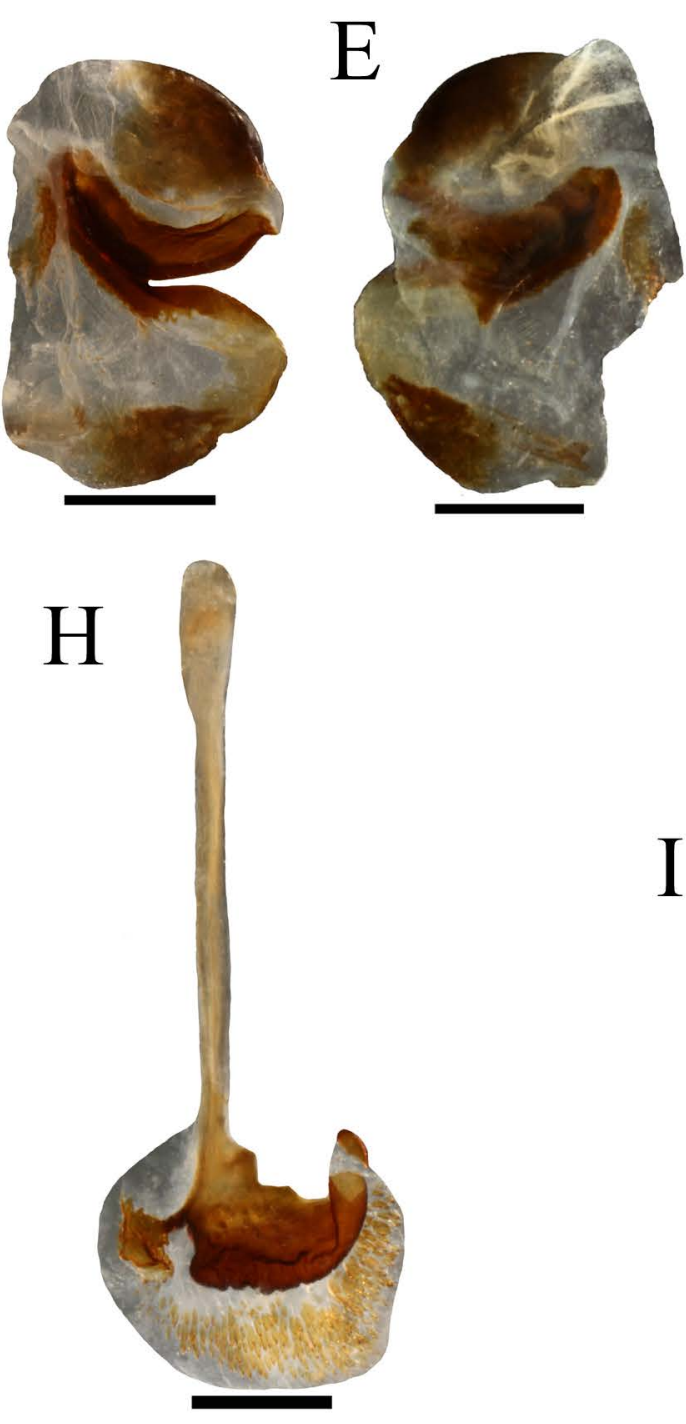

C
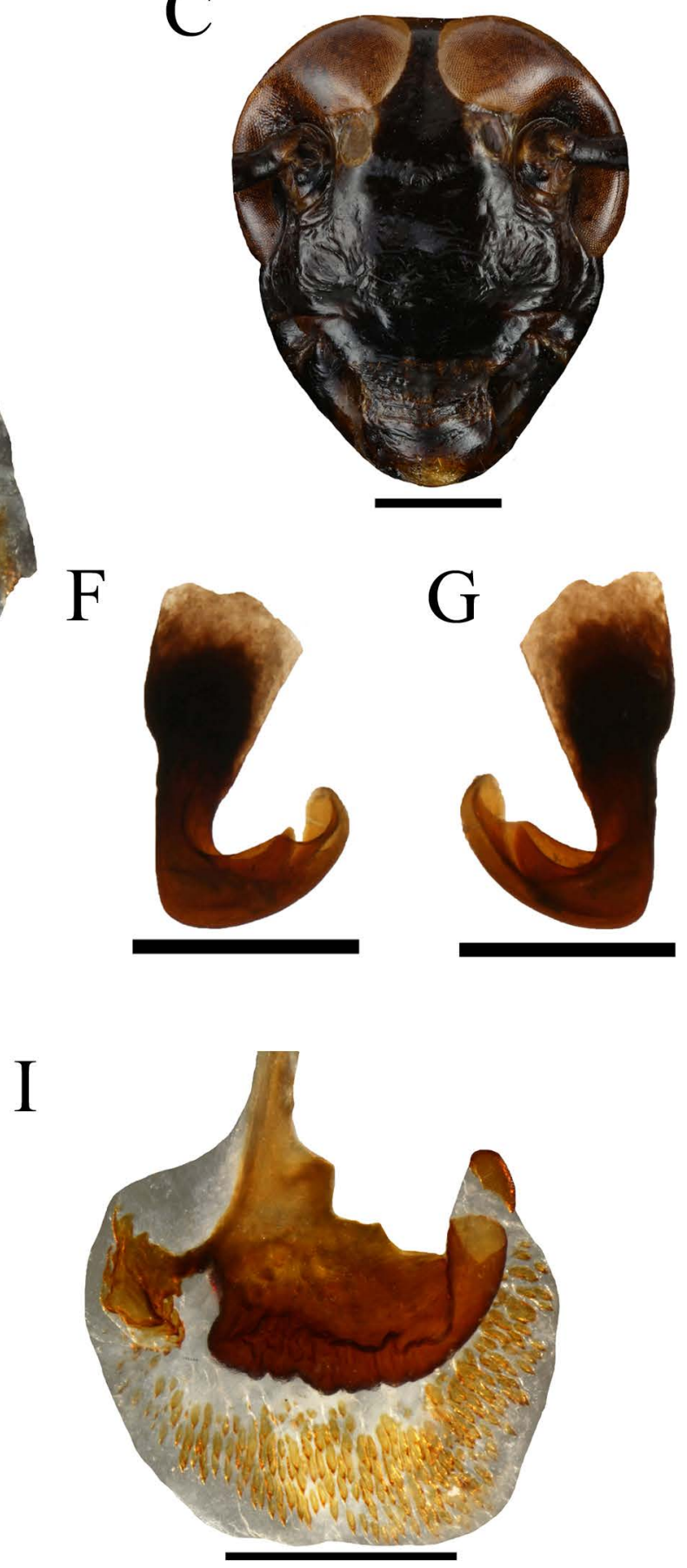

Figure 11 

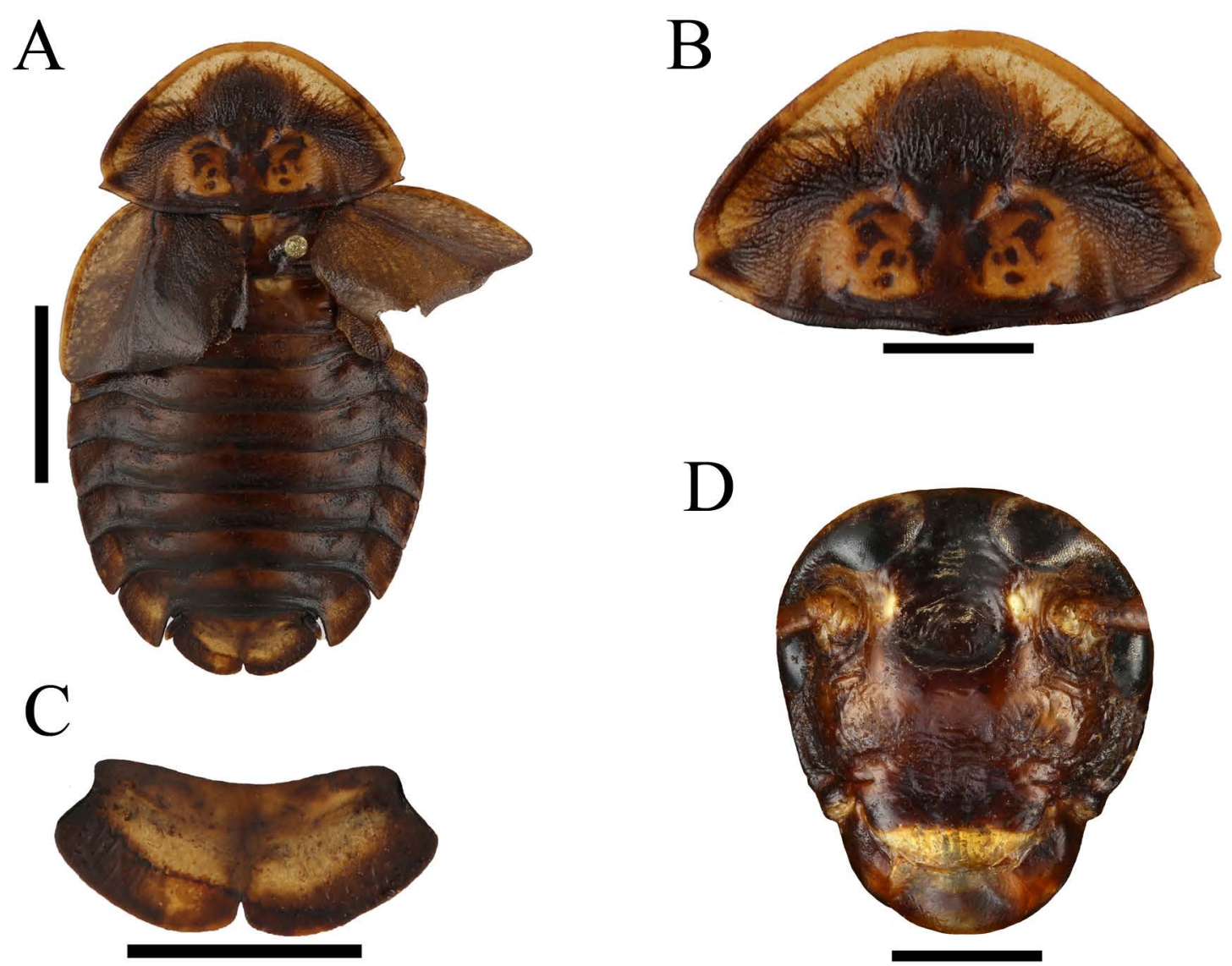

D
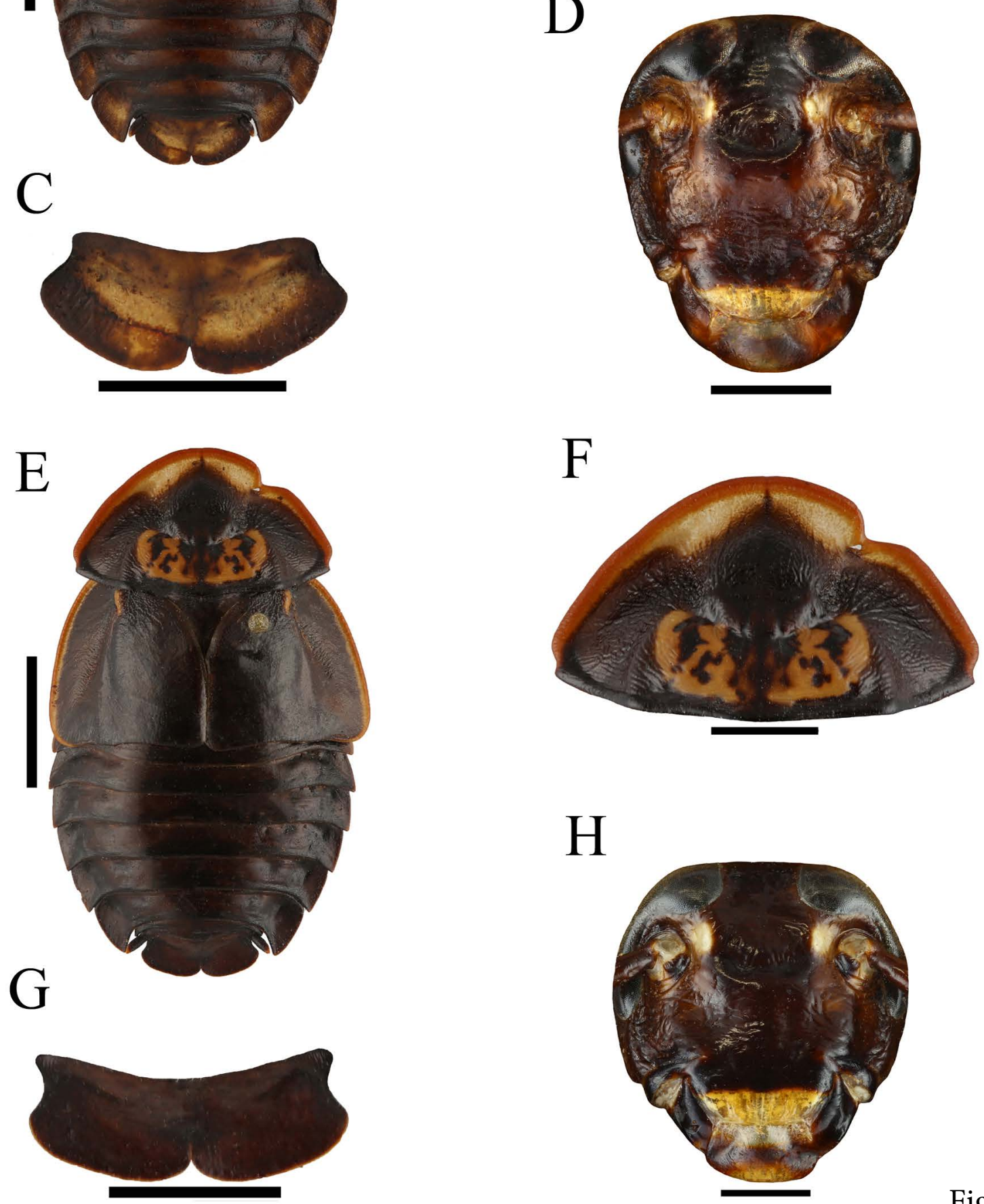

Figure 12 


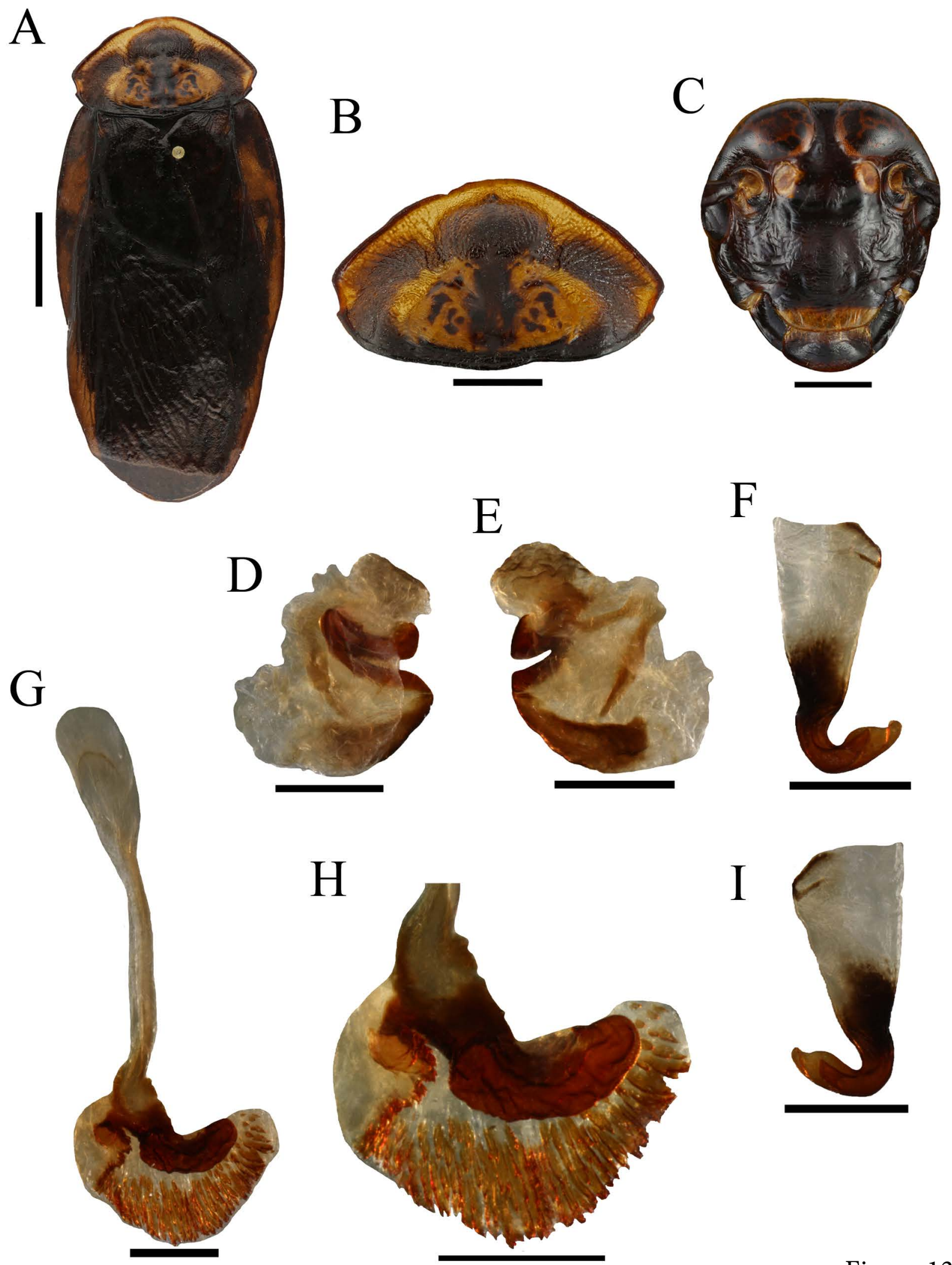

Figure 13 


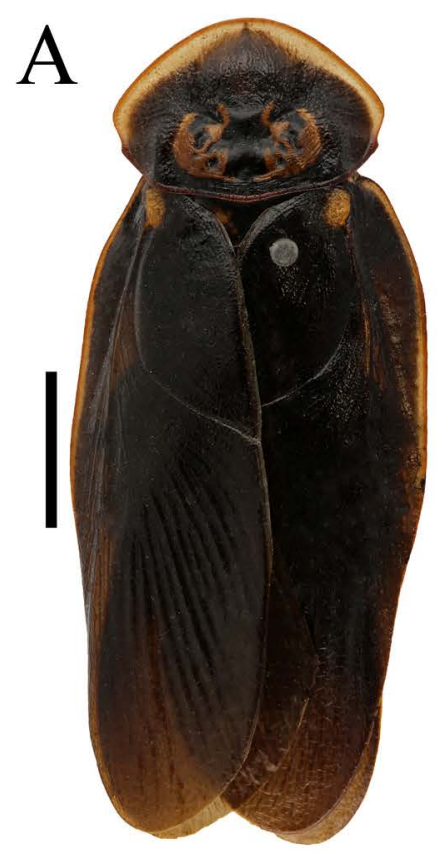

B

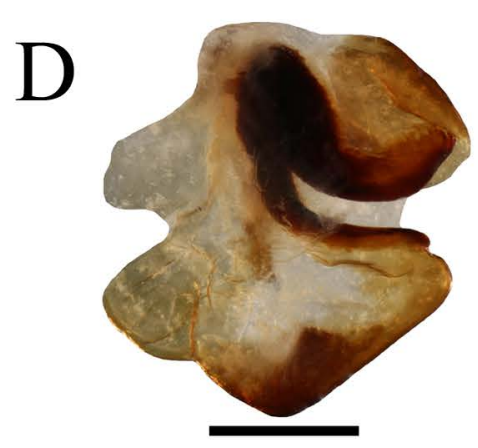

E

G

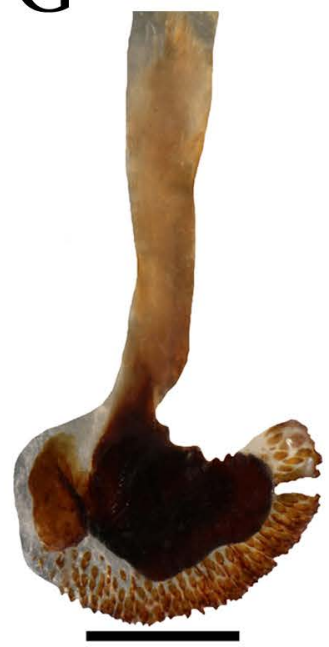

H
C



F


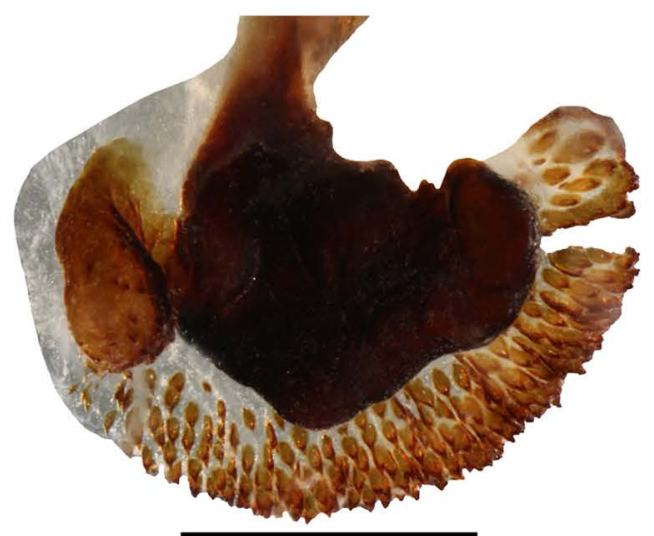

Figure 14 

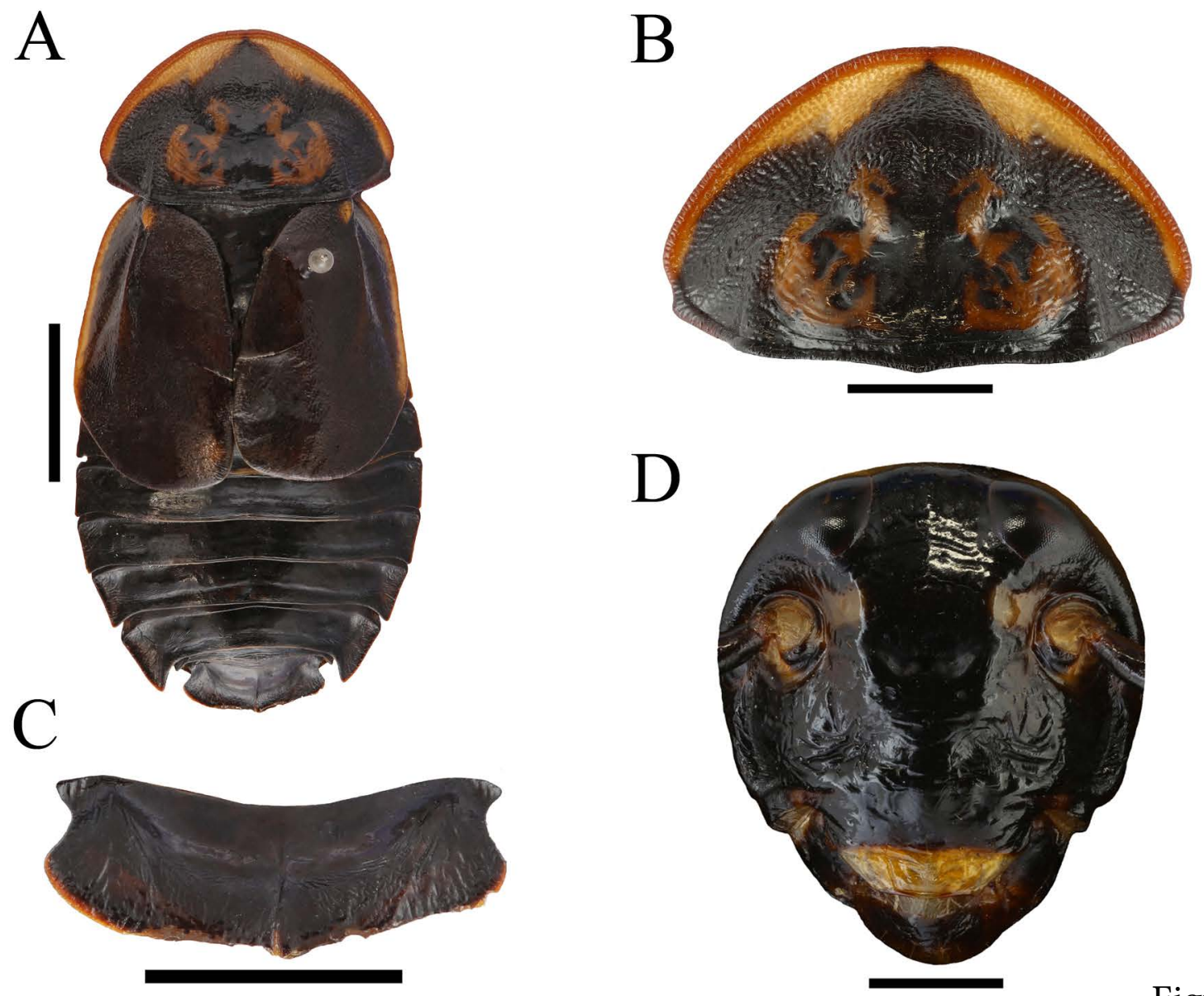

D

Figure 15 
A
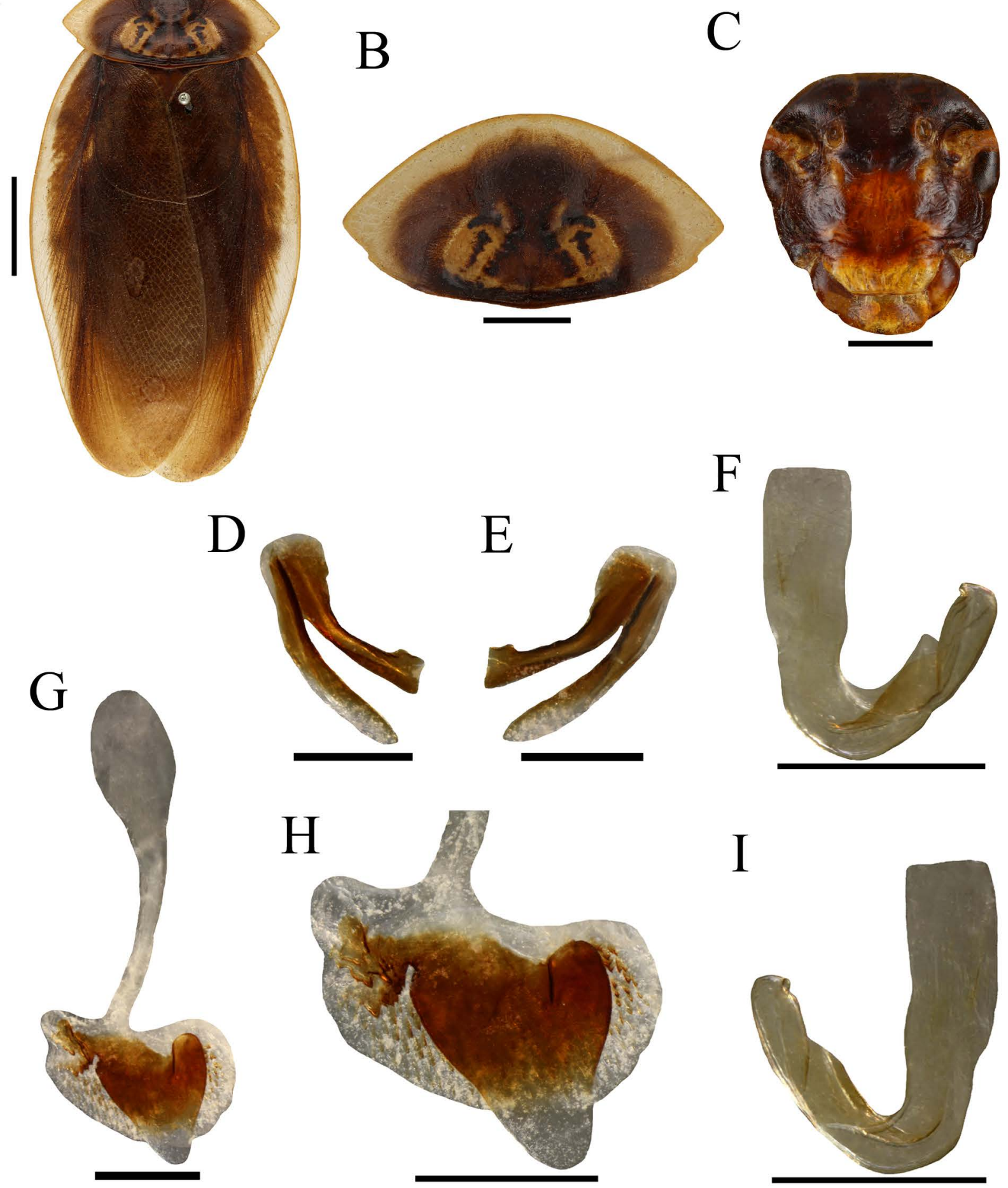

F
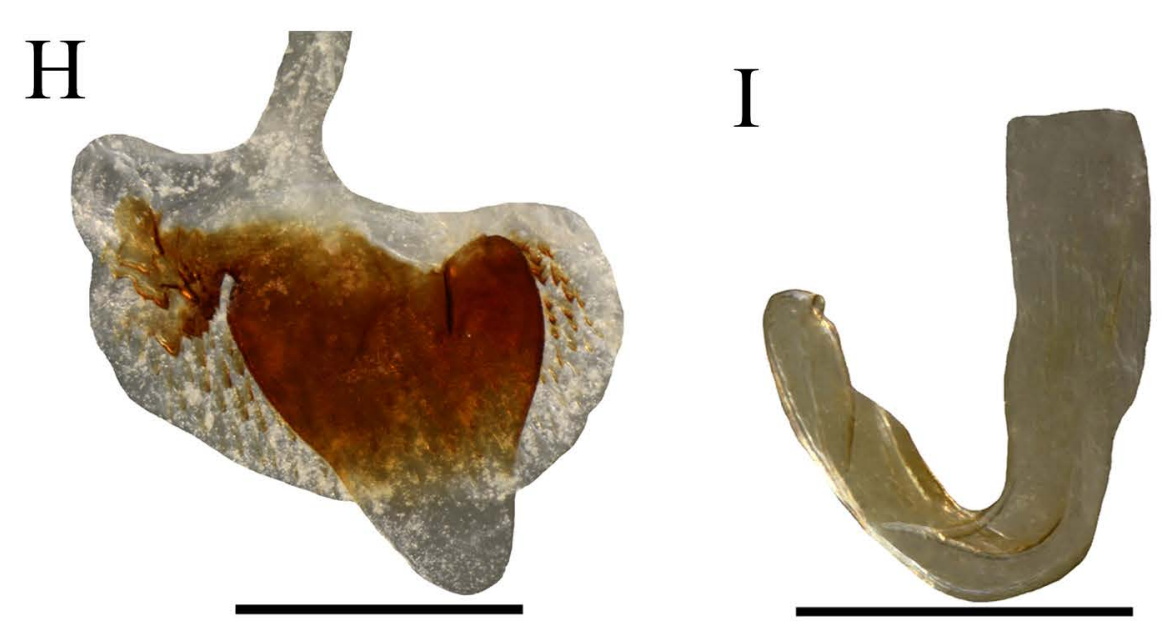

Figure 16 
O Monastria biguttata

$\square \quad$ Monastria similis

* Monastria cabocla

$\triangle$ Monastria itubera

○ Monastria itabuna

is Monastria kaingangue

$\diamond \quad$ Monastria sagittata

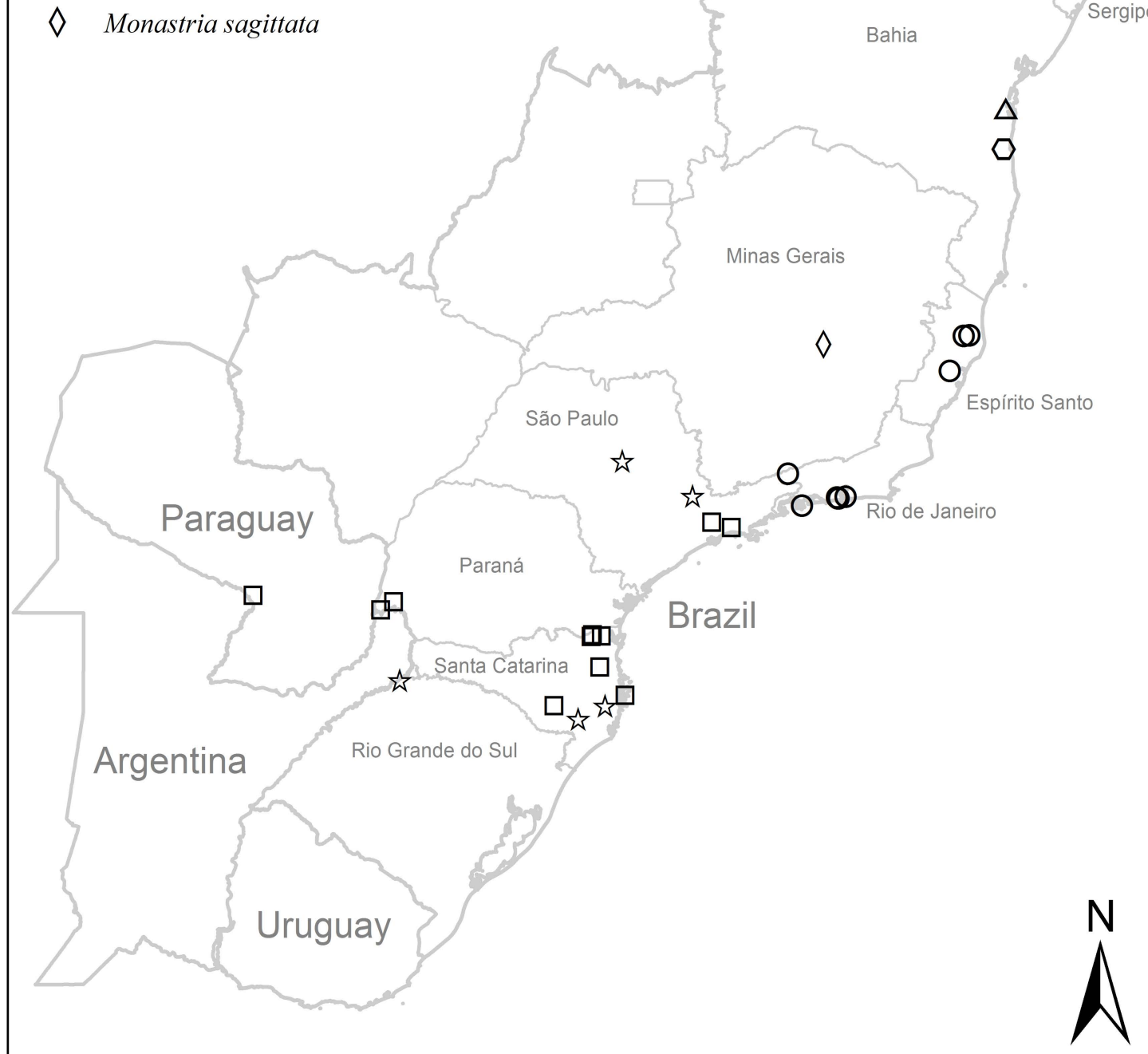

